\title{
The Global High Frequency Radar Network
}

\section{OPEN ACCESS}

Edited by:
Sabrina Speich,
École Normale Supérieure, France
Reviewed by:
Jeffrey Dean Paduan,
Naval Postgraduate School,
United States
Rosemary Anne Morrow,
UMR5566 Laboratoire d'Etudes en
Géophysique et Océanographie
Spatiales (LEGOS), France
*Correspondence:
Hugh Roarty
hroarty@marine.rutgers.edu

Specialty section:

This article was submitted to

Ocean Observation,

a section of the journal

Frontiers in Marine Science

Received: 20 November 2018 Accepted: 15 March 2019 Published: 14 May 2019

Citation:

Roarty H, Cook T, Hazard L,

George D, Harlan J, Cosoli S, Wyatt L, Alvarez Fanjul E, Terrill E,

Otero M, Largier J, Glenn S, Ebuchi N, Whitehouse B, Bartlett K,

Mader J, Rubio A, Corgnati L,

Mantovani C, Griffa A, Reyes E,

Lorente $P$, Flores-Vidal $X$, Saavedra-Matta KJ, Rogowski $P$.

Prukpitikul S, Lee S-H, Lai J-W, Guerin C-A, Sanchez J, Hansen B and Grilli $S$ (2019) The Global High

Frequency Radar Network.

Front. Mar. Sci. 6:164.

doi: 10.3389/fmars.2019.00164
Hugh Roarty ${ }^{*}$, Thomas Cook², Lisa Hazard², Doug George ${ }^{3}$, Jack Harlan', Simone Cosoli5, Lucy Wyatt ${ }^{6}$, Enrique Alvarez Fanjul', Eric Terrill' ${ }^{2}$, Mark Otero², John Largier ${ }^{3}$, Scott Glenn', Naoto Ebuchi ${ }^{8}$, Brian Whitehouse ${ }^{9}$, Kevin Bartlett ${ }^{10}$, Julien Mader ${ }^{11}$, Anna Rubio ${ }^{11}$, Lorenzo Corgnati12, Carlo Mantovani12, Annalisa Griffa'12, Emma Reyes ${ }^{13}$, Pablo Lorente7, Xavier Flores-Vidal'14, Kelly Johanna Saavedra-Matta ${ }^{14}$, Peter Rogowski ${ }^{2}$, Siriluk Prukpitikul'15, Sang-Ho Lee ${ }^{16}$, Jian-Wu Lai'7, Charles-Antoine Guerin ${ }^{18}$, Jorge Sanchez ${ }^{19}$, Birgit Hansen ${ }^{20}$ and Stephan Grilli21

\footnotetext{
1 Department of Marine and Coastal Sciences, Rutgers, The State University of New Jersey, New Brunswick, NJ, United States, ${ }^{2}$ Scripps Institution of Oceanography, Coastal Observing Research and Development Center, La Jolla, CA, United States, ${ }^{3}$ Coastal and Marine Sciences Institute, University of California, Davis, Davis, CA, United States, ${ }^{4}$ United States Integrated Ocean Observing System Program Office, NOAA, Silver Spring, MD, United States, ${ }^{5}$ Ocean Graduate School and UWA Oceans Institute, The University of Western Australia, Crawley, WA, Australia, ${ }^{6}$ School of Mathematics and Statistics, The University of Sheffield, Sheffield, United Kingdom, ${ }^{7}$ Puertos del Estado, Madrid, Spain, ${ }^{8}$ Institute of Low Temperature Science, Hokkaido University, Sapporo, Japan, ${ }^{9}$ OEA Technologies Inc., Upper Tantallon, NS, Canada, ${ }^{10}$ Ocean Networks Canada, Victoria, BC, Canada, ${ }^{11}$ AZTI Marine Research, Pasaia, Spain, ${ }^{12}$ Institute of Marine Sciences, National Research Council of Italy, Lerici, Italy, ${ }^{13}$ ICTS SOCIB, Palma, Spain, ${ }^{14}$ Instituto de Investigaciones Oceanologicas, Universidad Autónoma de Baja California, Ensenada, Mexico, ${ }^{15}$ Geo-Informatics and Space Technology Development Agency, Bangkok, Thailand, ${ }^{16}$ Kunsan National University, Gunsan, South Korea, ${ }^{17}$ NARLabs, Taiwan Ocean Research Institute (TORI), Taipei, Taiwan, ${ }^{18}$ Mediterranean Institute of Oceanography, University of Toulon, Toulon, France,

${ }^{19}$ Qualitas Remos, Madrid, Spain, ${ }^{20}$ HELZEL Messtechnik GmbH, Kaltenkirchen, Germany, ${ }^{21}$ Department of Ocean Engineering, University of Rhode Island, Kingston, Rl, United States
}

Academic, government, and private organizations from around the globe have established High Frequency radar (hereinafter, HFR) networks at regional or national levels. Partnerships have been established to coordinate and collaborate on a single global HFR network (http://global-hfradar.org/). These partnerships were established in 2012 as part of the Group on Earth Observations (GEO) to promote HFR technology and increase data sharing among operators and users. The main product of HFR networks are continuous maps of ocean surface currents within $200 \mathrm{~km}$ of the coast at high spatial (1-6 km) and temporal resolution (hourly or higher). Cutting-edge remote sensing technologies are becoming a standard component for ocean observing systems, contributing to the paradigm shift toward ocean monitoring. In 2017 the Global HFR Network was recognized by the Joint Technical WMO-IOC Commission for Oceanography and Marine Meteorology (JCOMM) as an observing network of the Global Ocean Observing System (GOOS). In this paper we will discuss the development of the network as well as establishing goals for the future. The U.S. High Frequency Radar Network (HFRNet) has been in operation for over 13 years, with radar data being ingested from 31 organizations including measurements from Canada and Mexico. HFRNet currently holds a collection from over 150 radar installations totaling millions of records of surface ocean velocity measurements. During the past 10 years in Europe, 
HFR networks have been showing steady growth with over 60 stations currently deployed and many in the planning stage. In Asia and Oceania countries, more than 110 radar stations are in operation. HFR technology can be found in a wide range of applications: for marine safety, oil spill response, tsunami warning, pollution assessment, coastal zone management, tracking environmental change, numerical model simulation of 3-dimensional circulation, and research to generate new understanding of coastal ocean dynamics, depending mainly on each country's coastal sea characteristics. These radar networks are examples of national inter-agency and inter-institutional partnerships for improving oceanographic research and operations. As global partnerships grow, these collaborations and improved data sharing enhance our ability to respond to regional, national, and global environmental and management issues.

Keywords: remote sensing, high frequency radar, ocean currents, waves, tsunami, boundary currents, ocean observing system

\section{INTRODUCTION}

Ocean currents regulate the climate by carrying warm water from the equator toward the poles. The ability to measure these currents will allow us to monitor and hopefully predict the trajectory of our climate. Western boundary currents are important areas for understanding and measuring the oceans impact on and response from climate processes (Send et al., 2009). Approximately 1.2 billion people (23\% of the world population) live within $150 \mathrm{~km}$ of the coast (Small and Nicholls, 2003). These populations are projected to increase as more people migrate to the coast. This current and projected population will put a strain on coastal ecosystems because of the resources that humans extract from the coast as well as the waste we dispose of in the coastal ocean. Coastal ocean health is critical for human health because humans are exposed to disease causing organisms in this interface (Stewart et al., 2008). Therefore, it is essential to improve existing and develop new coastal management techniques and strategies in order to protect the world's most critical ecosystems (Boesch et al., 2000). Quantifying coastal ocean currents is one such tool to manage the ecosystem. There are several different methods in order to accomplish this. Surface drifters (Lumpkin et al., 2013) provide an accurate measurement of surface drift with high temporal resolution. The drawbacks of this platform are the short-lived nature of the surface floats (order 1 month in a given region like those used in the Global Drifter Program or due to battery life like those used by the United States Coast Guard). Acoustic Doppler Current Profilers (ADCPs) provide single-point or along-track velocity current data with high temporal resolution with measurements throughout the water column. ADCPs with a servicing interval on the order of 1 year carry with it the high cost of ship time to deploy and service the mooring. Satellite-altimetry derived currents provide valuable insights on large-scale geostrophic ocean circulation, but satellite observations of currents near the coast are poor for a few reasons: (i) the sampling strategy was not designed for near-coast regions, (ii) altimetry observations are of lower accuracy near the coast due to land contaminations (altimeter and radiometer), (iii) inaccurate removal of atmospheric effects at the surface and incorrect tidal corrections (Vignudelli et al., 2005; Liu and Weisberg, 2007).

Oceanographic HFRs have been identified as a cost-effective complement to in situ systems by providing increased spatial coverage (Fujii et al., 2013). The measurement is typically confined to the coastal zone and can be effective to fill the gaps of other monitoring platforms, such as satellite-based sensors, but with much higher temporal resolution. HFR derived ocean surface currents are a remotely sensed measurement typically collected with land-based sensors, which reduces operations and maintenance budgets for collection of the data as compared to ship-based and moored sensors. There have been measurements with HFR in the open ocean aboard large oil platforms (Lipa et al., 1990) but the vast majority of platforms are located along coastlines. Additionally, HFR operates continuously, and with proper maintenance, is capable of observing time-series with high temporal resolution and longtime records (some sites operating for two decades). These measurements allow for both Eulerian and Lagrangian estimates of the flow field (Ohlmann et al., 2007).

Coastal radars typically operate in the HF and UHF radio bands $(3-50 \mathrm{MHz})$, and transmit and receive a ground wave that couples to the salty sea water surface (Figure 1). There have been oceanographic applications of sky wave signals (Anderson, 1986; Headrick and Thomason, 1998) but the large size and cost of these systems have not made them a viable option for the oceanographic community. The traditional measurement of the HFR using groundwave propagation is a radial map of currents derived once an hour (Figure 2), but higher temporal resolution sampling schemes are occasionally utilized (Piedracoba et al., 2016). Because of the long radio wavelengths at HF (100 m $10 \mathrm{~m}$ ) the receive antennas are kept stationary to look in different directions compared to microwave antennas that are typically rotated to determine bearing. Bearing determination, as it relates to measuring ocean surface currents with HFR, describes the method used by the radar to determine direction of arrival of the signal echo. This processing step is divided into two groups, direction-finding and beam-forming (aka phased array). Direction-finding (compact array) radars, such as the Coastal Ocean Dynamic Application Radar (CODAR) SeaSonde 


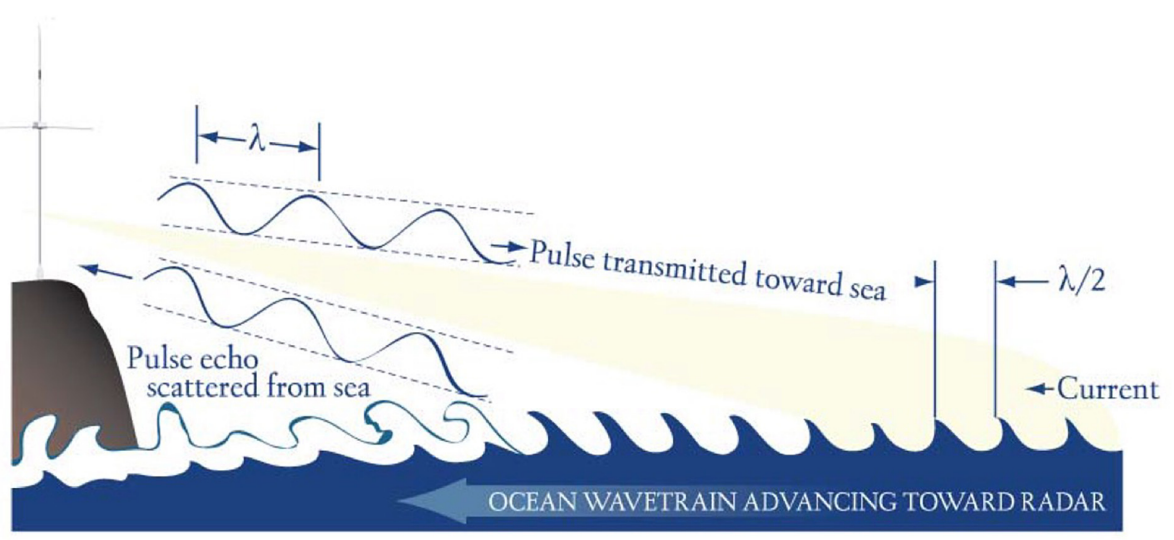

FIGURE 1 | Schematic figure depicting the Bragg scattering process that allows for ocean current measurements with High Frequency radio signals. The echo scattered from the sea is amplified when the transmitted radio signal encounters an ocean wave that has a wavelength that is half the wavelength of the radio signal.

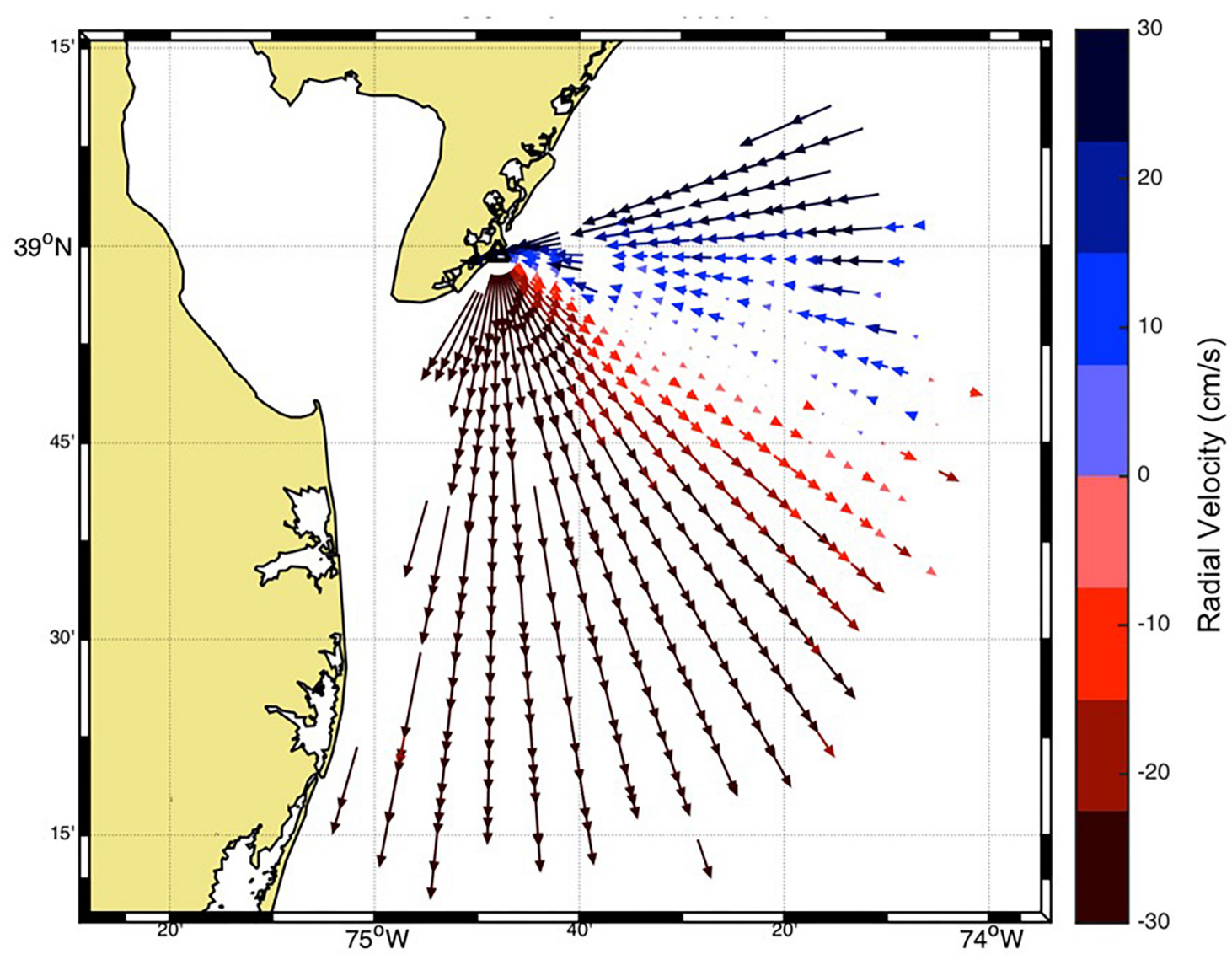

FIGURE 2 | Radial map of ocean currents derived from an HF radar station (triangle). The blue vectors denote surface currents towards the radar station while red vectors show currents away from the radar.

(Barrick and Lipa, 1985), compare the phases and amplitudes of radio signals received by closely spaced antenna elements coupled with various direction-finding inversion algorithms. Beamforming radars adjust the amplitude and phase of the received signal through an array of antennas to determine bearing (de
Paolo and Terrill, 2007). Early versions of this radar type included the Ocean Surface Current Radar (OSCR) and Pisces. The radar models available as of this manuscript with a beam-forming design include the Pisces (Wyatt et al., 2006), the WEllen RAdar -WERA- (Helzel et al., 2007) and LERA (Flament et al., 2016). 
Regardless of the manufacturer, the positive contribution of commercial HFR systems to retrieve realistic wave and surface current information has been unequivocally proven.

A recent advancement in the radar technology is the bistatic measurement (Lipa et al., 2009; Baskin et al., 2016) where the transmitter and receiver are geographically separated which yields an elliptical map of ocean surface currents. The radial or elliptical measurements from multiple stations are combined via a variety of combining methods to produce an hourly map of total currents (Figure 3) typically, once an hour. An ensemble of total vector files can be used to generate a trajectory model of virtual surface drifters to demonstrate the fate of particles on the surface (Figure 4). The readers are referred to Paduan and Washburn (2013) for a thorough discussion of oceanographic HFR theory, development, and applications.

The information contained in the second order region, of much lower amplitude than the first order peak, are utilized to obtain the wave information, i.e., height, centroid period and direction or the full directional spectrum and derived parameters (Wyatt et al., 2011). Wave measurements are obtained using some version of the theory of Barrick (1977). The current techniques for wave measurements range from empirical methods, which relate wave parameters (significant wave height) to an integral of the second order Doppler spectrum, to full numerical inversions, which can provide the ocean wave directional spectrum if the quality of the radar data is good enough. The frequency of the radar determines the maximum and minimum wave height that can be measured by any system. The lower the frequency the higher the wave height that can be measured. For example, the maximum wave height that can be measured at $25 \mathrm{MHz}$ is $4 \mathrm{~m}$ however it is $20 \mathrm{~m}$ at $5 \mathrm{MHz}$ operating frequency (Lipa and Nyden, 2005). Below the minimum threshold, the lower-energy second-order spectrum is closer to the noise floor and more likely contaminated with spurious contributions that might result in wave height overestimation or limited temporal continuity in wave measurements. Above the maximum threshold, the first-order peak merges with the second-order one and the interpretation of the spectra becomes impossible with existing methods. In this context, recent efforts have been focused on the improvement of wave height estimation for highly variable sea states by using dual-frequency HFR systems (Wyatt and Green, 2009). HFR-derived wave measurements also have a broad range of practical applications and can be used as benchmark for wave model skill assessment (Lorente et al., 2018), as input for assimilation into SWAN or Wavewatch III models (Waters et al., 2013), or for the analysis of extreme wave height events (Atan et al., 2015).

HFR can also be used to estimate wind speed and direction but are not yet robust enough for operational use. The ratio of two first order peaks can be utilized to estimate wind direction (Fernandez et al., 1997; Wyatt, 2018). Estimates of wind speed have also been obtained from the second order peaks (Kirincich, 2016).

The initial "coming of age" for HFR occurred between 2000 and 2010, in which real-time HFR data was accepted as a reliable operational tool. For example, surface current data is ingested in the United States (US) by federal and state group for search and rescue (SAR), oil spill and other operational protocols in coastal waters. Success stories have emerged over the past decade from the United States and elsewhere, as well as examples where the importance of HFR surface currents data was noted (e.g., Deep Water Horizon oil spill in the Gulf of Mexico). The next phase for HFR applications involves the recognition of the value of long-term, high-resolution surface currents for tracking environmental change and marine resources, including coastal water quality, coastal ecosystems and fisheries. This second coming of age is imminent with data sets of over 10 years now available from the west and east coasts of the United States as well as from northern Japan.

The Global High Frequency Radar Network was established in 2012 as part of the Group on Earth Observations 2012-2015 Work Plan (Roarty et al., 2014). A series of meetings were held to jump start the collaboration England 2012, Norway 2013, Taiwan 2014, Crete 2015, and finally the United States in 2016 (Roarty et al., 2016). This series of meetings introduced the radar network to global organizations like the Global Ocean Observing System (GOOS) and the Joint Technical Commission for Oceanography and Marine Meteorology (JCOMM). JCOMM coordinates oceanographic measurements, data and services between the Intergovernmental Oceanographic Commission (IOC) and the World Meteorological Organization (WMO). The GOOS is executed within the IOC. In 2017 the Global HFR Network along with ocean gliders were recognized by JCOMM as an observing network of GOOS.

\section{DEVELOPMENT OF NETWORKS}

Academic, government, and private organizations from around the globe have established high frequency radar (HFR) networks at regional or national levels to support scientific and operational activities along the coast. The growth of the network remains steady with approximately 400 stations currently operating and collecting real-time surface current information. There are approximately 281 sites reporting to the GEO list as of 2018. The United States and Europe have tracked the growth of this sensor technology versus time (Figure 5). Approximately 140 installations are active in the Asia-Pacific region, and this number is expected to grow with new installations in the Philippines and Vietnam. HFR systems have also been recently installed in South Africa. The number of organizations displaying surface current information on the Global Network page has also increased from 7 in November 2016 to 13 in May 2017. The organizations currently providing surface current information to the Global Network are shown in Table 1.

The Global Network has been organized according to the International Telecommunication Union (ITU) regions (Figure 6). Region 1 encompasses Europe, Africa and northern Asia. Region 2 covers the Americas and Region 3 comprises southern Asia and Oceania. In 2012 Resolution 612 was passed by the ITU establishing the use of the radiolocation service between 3 and $50 \mathrm{MHz}$ to support (high-frequency) oceanographic radar operations. This was an important first step for the community because it established the importance of HFR to 


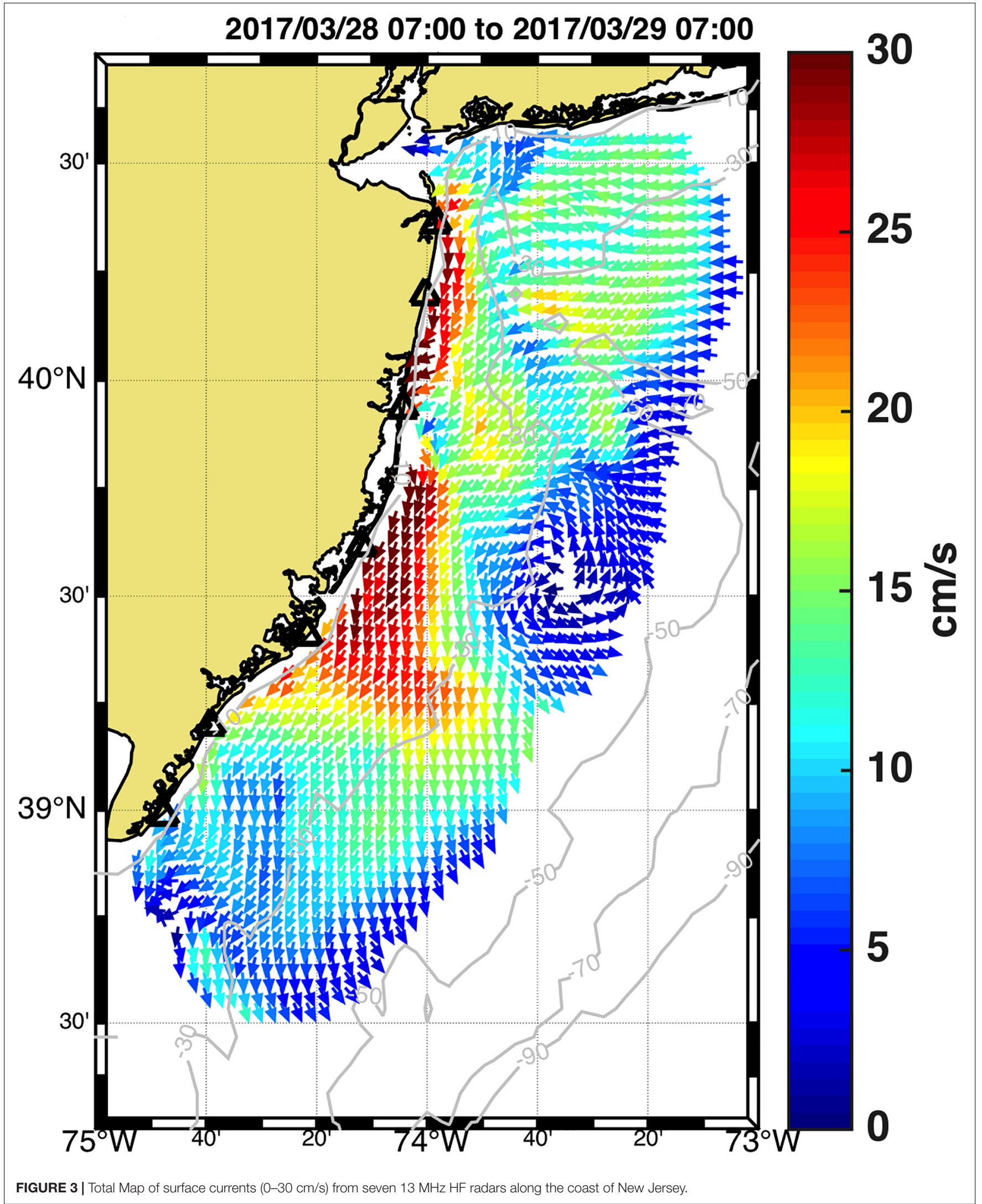


receive designation in frequency space for the operation of the radars. There is still more work to be done because while the ITU sets global standards, each region and country within will set specific service rules and licensing regulations. Acquiring a frequency allocation that allows HFR as a primary user is a current goal for the community, as interference within HF bands greatly impacts HFR performance.

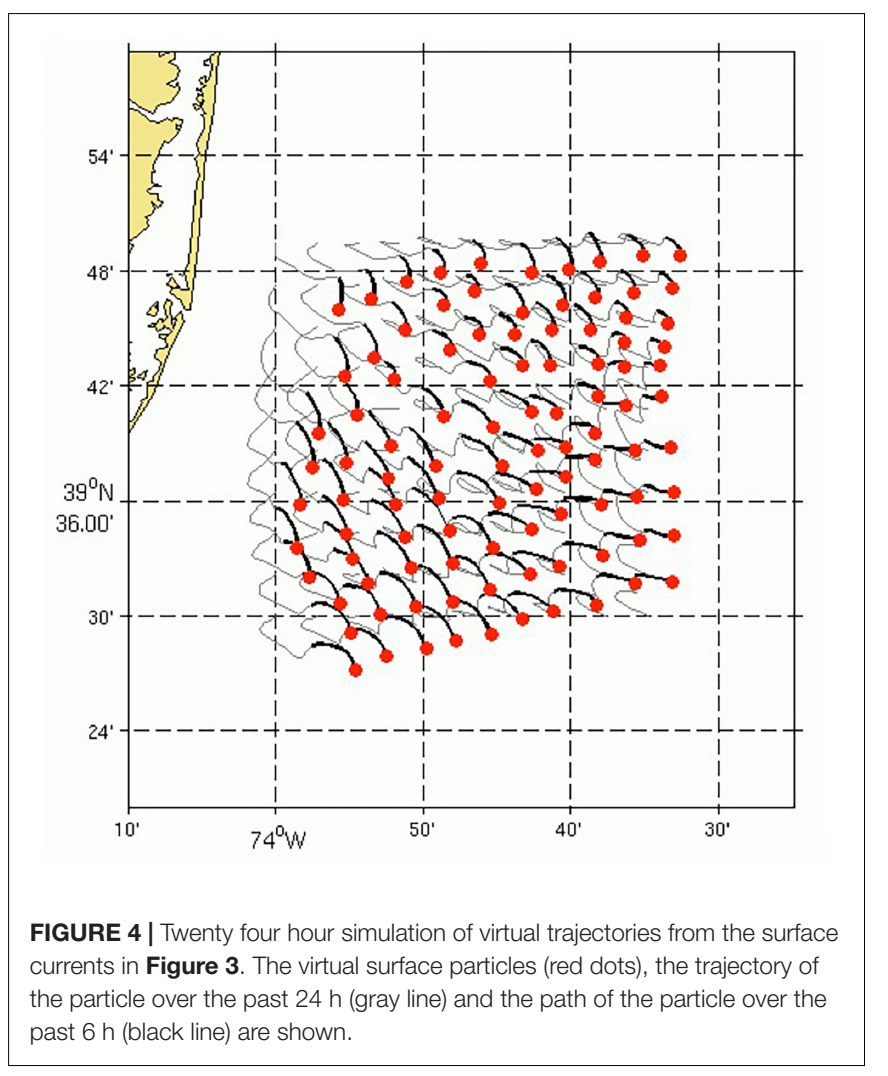

Here is a brief description on the history and present status of HFR networks within the Global regions.

\section{Europe, Africa and Middle East (Region 1)}

In Europe (EU), the use of HFR systems is growing with over 62 HFR sites currently operating and a number in the planning stage. A survey to catalog the status of different HFR systems available in the Europe was launched in June 2016 and has been maintained up to date (Mader et al., 2016). The survey gathered responses from 28 European institutions and information on more than 70 HFR systems. From 2004 until 2009 a moderate growth rate of two new HFRs per year was observed and, since 2009, it has increased to around six new HFRs installed per year and up to seven, since 2016 (Figure 5B). The most popular identified user of the EU HFR data was academia, followed by European or national maritime safety agencies and weather services (Rubio et al., 2017). The most popular research lines were those related to Lagrangian approaches to surface transport and connectivity (e.g., Menna et al., 2007; Abascal et al., 2009; Uttieri et al., 2011; Berta et al., 2014a; Berta M. et al., 2014b; Bellomo et al., 2015; Solabarrieta et al., 2016; Cianelli et al., 2017), data assimilation and the validation and calibration of numerical ocean forecasting models especially near the coast (e.g., Barth et al., 2008, 2011; Marmain et al., 2014; Stanev et al., 2015; Iermano et al., 2016; Lorente et al., 2016; Hernández et al., 2017) and small scale and mesoscale ocean processes (e.g., Sentchev et al., 2013; Berta et al., 2018; Hernández-Carrasco et al., 2018; Rubio et al., 2018a).

The European contribution to the Global Network is on a volunteer basis and no dedicated funding is allocated directly to the providers for a coordinated effort. The European coordination of HFR systems started with the EuroGOOS HFR Task Team (TT) in 2014, which increased the global visibility of the European HFR systems and enabled a joint integration
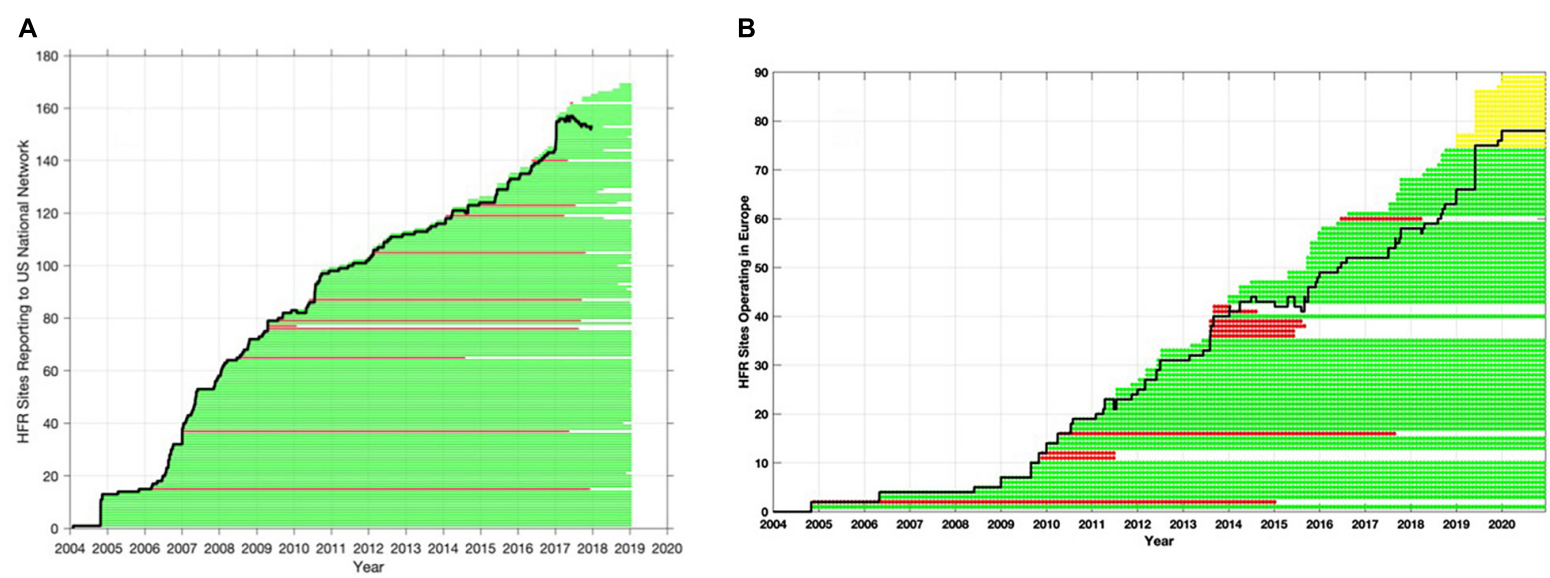

FIGURE 5 | Growth of HF radar networks in the past two decades. (A) Number of radar stations reporting to the United States National Network (bold black line) from 2004 to 2018. (B) Temporal evolution of operational HFR systems in Europe from 2004 to 2022 (bold black line). The timeline of each of the HFR installations is provided by the discontinuous horizontal lines. Past systems or those no longer providing operational data are plotted in red, future deployments in yellow and operational systems in green. 
TABLE 1 | List of countries and organizations providing surface current information to the Global HF Radar Network.

\begin{tabular}{|c|c|c|}
\hline Number & Country & Organization \\
\hline 1 & Australia & Integrated Marine Observing System \\
\hline 2 & Canada & Ocean Networks Canada \\
\hline 3 & Croatia & Institute of Oceanography and Fisheries \\
\hline 4 & Germany & $\begin{array}{l}\text { Helmholtz-Zentrum Geesthacht Centre for Materials } \\
\text { and Coastal Research }\end{array}$ \\
\hline \multirow[t]{2}{*}{5} & Italy & CNR, Consiglio Nazionale delle Ricerche \\
\hline & & $\begin{array}{l}\text { OGS, Istituto Nazionale di Oceanografia e di } \\
\text { Geofisica Sperimentale }\end{array}$ \\
\hline \multirow[t]{2}{*}{6} & Malta & $\begin{array}{l}\text { University of Malta, Physical Oceanography Unit } \\
\text { (PO-Unit), }\end{array}$ \\
\hline & & $\begin{array}{l}\text { International Ocean Institute-Malta Operational } \\
\text { Centre (IOI-MOC) }\end{array}$ \\
\hline 7 & Mexico & $\begin{array}{l}\text { Observatorio de Corrientes Oceánicas MEXicanas } \\
\text { (OCOMEX) }\end{array}$ \\
\hline \multirow[t]{6}{*}{8} & Spain & Puertos del Estado \\
\hline & & $\begin{array}{l}\text { SOCIB, Balearic Islands Coastal Observing and } \\
\text { Forecasting System }\end{array}$ \\
\hline & & Meteorological Agency (Euskalmet) \\
\hline & & INTECMAR \\
\hline & & Universidad de Vigo \\
\hline & & Universidad de Cádiz \\
\hline 9 & Taiwan & TOROS (Taiwan Ocean Radar Observing System) \\
\hline 10 & United States & Integrated Ocean Observing System (IOOS) \\
\hline
\end{tabular}

in the Global Network. From its conception the EuroGOOS HFR TT has ensured a close exchange with the GEO Global HF radar network and participated in GEO Global HF radar task meetings. The two European co-chairs of the GEO Global HF radar task are members of the EuroGOOS HFR TT core group, and this institutional collaboration should continue in the future. In addition, the definition of the EU HFR data standard has been developed by the EuroGOOS HFR TT in close collaboration with the EU and US.

In 2018, the HFR EU data node was created as a centralized European competence center to ensure the implementation of the HFR data stream (harvesting, harmonization, formatting, and distribution) from the data providers toward the different EU marine data portals and global data infrastructures. A plan for the inclusion of HFR data into the Copernicus Marine Environment Monitoring Service (CMEMS) through this EU data node is in progress. First steps toward this integration were carried out under the CMEMS INCREASE Project (Rubio et al., 2018b). A survey of the CMEMS community by the INCREASE project highlighted the interest shown in having access to HFR current data at a global level and to operational data derived from the advanced processing of the HFR backscatter signals, such as waves and maps of wind direction, which opens future working lines.

The CMEMS In Situ Thematic Centre (CMEMS-INSTAC), will start delivery of near-real time (NRT) total and radial HFR data from certain sites in April 2019 and April 2020, respectively. The data distribution will be made both at a global and regional level, aiming to foster the relationship between users, providers, and the INSTAC regional components inside the regional alliances of EuroGOOS (ROOSes). Other European HFR operators will be supported in their preparation of their involvement, in order to achieve the final goal of distributing all European HFR data within CMEMS-INSTAC, SeaDataCloud and EMODnet platforms.

Inside CMEMS-INSTAC the HFR data set is considered part of a global product of ocean surface currents, and will be delivered jointly with the global surface drifter data set. The CMEMS structure is thus ready to embrace a global dimension for the HFR data. Work is underway to prepare for the inclusion of United States HFR data from the United States IOOS National HFR Node into the CMEMS-INSTAC Global Distribution Unit, planned for April 2020. This preparation phase is being developed with the MARACOOS (IOOS regional association in the Mid-Atlantic) network and is mainly focused on treating the dataflow and the few discrepancies between United States and European standard data models.

In parallel, the EU Project JERICO-NEXT is working to provide procedures and methodologies to enable HFR data to comply with the international standards regarding their quality and metadata, within the overall goal of integrating the European coastal observatories (Corgnati et al., 2018b).

The ongoing MyCoast project aims to build a coordinated coastal operational observatory in the Atlantic Ocean by improving the synergies between observational and forecasting systems. A dedicated work package is devoted to the analysis and enhancement of HFR-derived wave estimations and the subsequent application to extreme weather events and maritime safety. There is an ongoing effort and a considerable planned investment in the North-Western Mediterranean between Italy and France (Quentin et al., 2017), in the framework of the EU Interreg Maritime Program (projects IMPACT and SICOMARPLUS). The plan is to build a network of sixteen HFRs, nine of them already operating, covering $600 \mathrm{~km}$ of coastline between the two countries by the end of 2021. The general purpose, through the integration of the HFR data with numerical models and in situ measurements, is the development of operational tools in the field of SAR operations and protection of the marine environment. Lastly there is an effort in Europe taking place in the Malta Channel area between Sicily (Italy) and Malta where four HFRs are currently operating as part of the EU Interreg project CALYPSO. Three additional HFRs will be added inside 2019 to the CALYPSO network. The main goal of the CALYPSO project, led by the University of Malta and having the University of Palermo as the main Sicilian partner, is to support efficient response against the threat of marine oil spills and also to support SAR operations and improve security and safety at sea in the trans-boundary Mediterranean area between Malta and Sicily.

The reader is referred to Rubio et al. (2017) for a more thorough description of the HFR activities within Europe. Below are descriptions of new networks since this paper was published. In addition, we are aware of installations in Turkey, Israel, and South Africa that will be coming online soon.

\section{Morocco}

The National Meteorological Directorate of Morocco (DMN) operates a network of two $5 \mathrm{MHz}$ long-range HFRs (Bouksim et al., 2016) located in the Port of Casablanca and in 


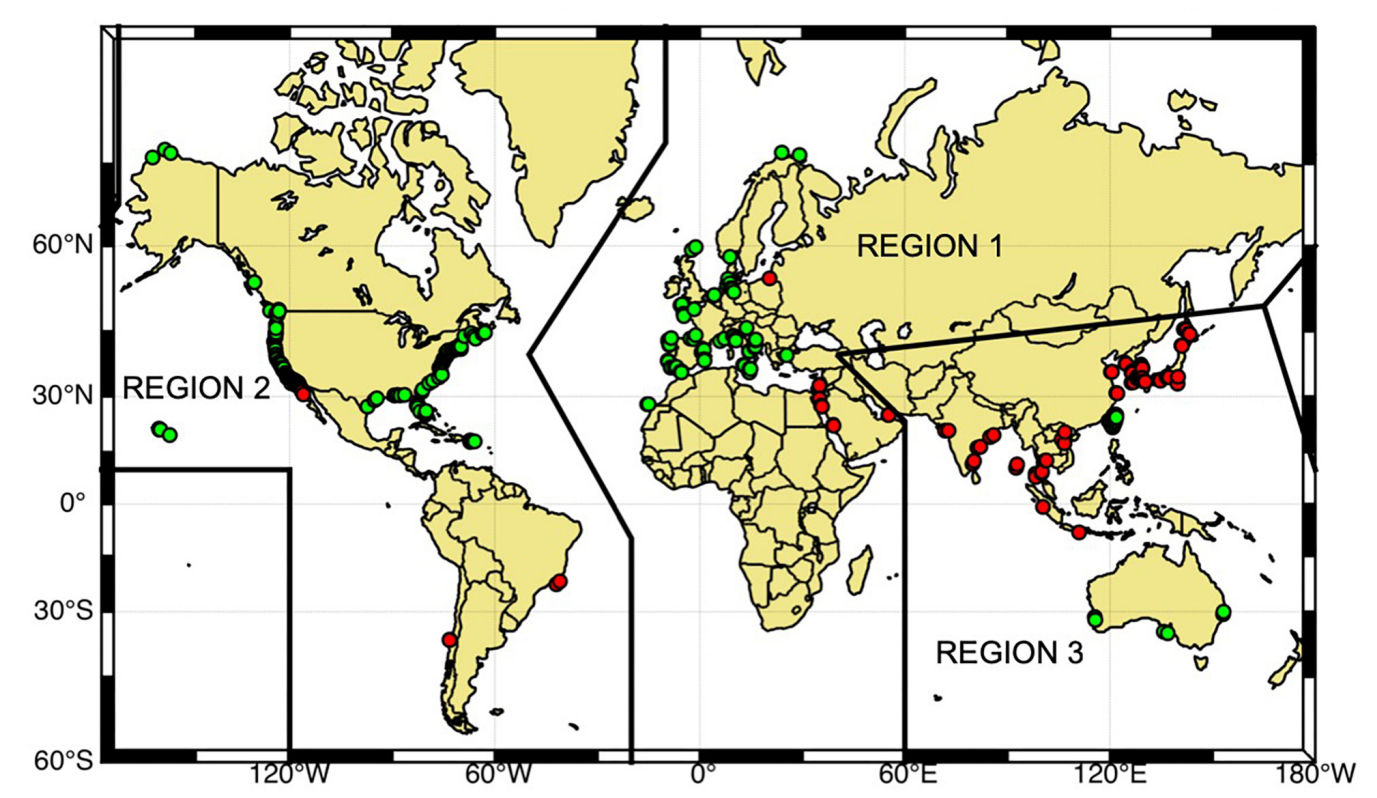

FIGURE 6 | Global distribution of HFR stations organized within the three regions of the International Telecommunications Union (ITU). The green dots indicate stations that are sharing their data through the global network and red dots indicate stations that are not currently sharing their data.

Temara with a measurement range of approximately $200 \mathrm{~km}$ offshore, covering an area of around 17,000 $\mathrm{km}^{2}$ between Casablanca and Rabat. This network was commissioned in April 2016 and represents the first permanent HFR network deployed in Africa. DMN is initially applying HFR surface currents and wave data to validate their operational marine forecast models and to improve their knowledge of the hydrodynamics in this part of the Moroccan coast. In future work, data will also be used for SAR operations, safety in navigation and for better preparedness and response against marine pollution incidents in collaboration with the Royal Moroccan Navy, National Ports Agency and Civil Protection Authority.

Future DMN plans include the extension of the current network to the South to cover the energy port of Jorf Lasfar and the installation of two additional HFRs in Tanger Med and Cap Malabata to monitor the Strait of Gibraltar. Data exchange with Spain is also envisioned to combine data of this new network with the already existing HFR network in this area operated by the Spanish National Harbour Authority (Puertos del Estado) in order to cover the whole strait.

\section{Saudi Arabia}

In 2015 King Abdullah University of Science and Technology (KAUST) and Saudi Aramco installed the first HFR network in the Kingdom of Saudi Arabia (KSA), composed of two $16 \mathrm{MHz}$ HFRs, monitoring surface currents and waves in the central Red Sea (Solabarrieta et al., 2018). One HFR is located at a KSA Coast Guard station in Rabigh pairing with the other set on the KAUST campus in Thuwal. Both stations provide hourly surface currents measurements up to a range of $70-100 \mathrm{~km}$ with a spatial resolution of $3 \mathrm{~km}$. The network was further expanded in 2017 to the North with the installation of two additional HFRs in Duba and Almuwaylih. KAUST owns two additional HFRs and plans to install these two units in the Southern part of the Red Sea inside 2019. Figure 7 shows the location of KAUST's current four radar network and envisioned location of the two additional units they plan to deploy in the Southern part of the Red Sea. Current use of the data is restricted to basic science, which will contribute to the Kingdom's fundamental understanding of ocean processes in the region. Some envisioned future applications include tracking of marine pollutants, fisheries management, safety of navigation and the design of marine protected areas.

\section{Portugal}

The Portuguese Hydrographic Institute (IH), the main operational oceanography institution in Portugal, operates a network of five CODAR HFRs (Fernandes, 2014). The network consists of two $13 \mathrm{MHz}$ HFRs deployed in 2010 deployed in São Julião and Espichel close to Lisbon and three $13 \mathrm{MHz}$ CODAR HFRs installed along the coast of the Algarve in Vila Real, Alfanzinha and Sagres inside the period 2012-2016 by the TRADE project $^{1}$. The main goal of the TRADE network is to improve safety in navigation and port operations in the Gulf of Cadiz, from the Straits of Gibraltar (Spain) to Cape St. Vicente (Portugal). Use of the Portuguese HFR data includes validation of numerical surface currents models, tracking of marine pollutants and use in SAR cases. A CODAR Tsunami Detection Software Package has recently been also installed on the Sagres HFR station as part of the OCASO project in order to develop tsunami detection algorithms that are adapted to the very complex bathymetry of the area. The IH has a mid-term plan to extend its HFR network to a total of 20 stations.

${ }^{1}$ http://www.tradehf.eu 


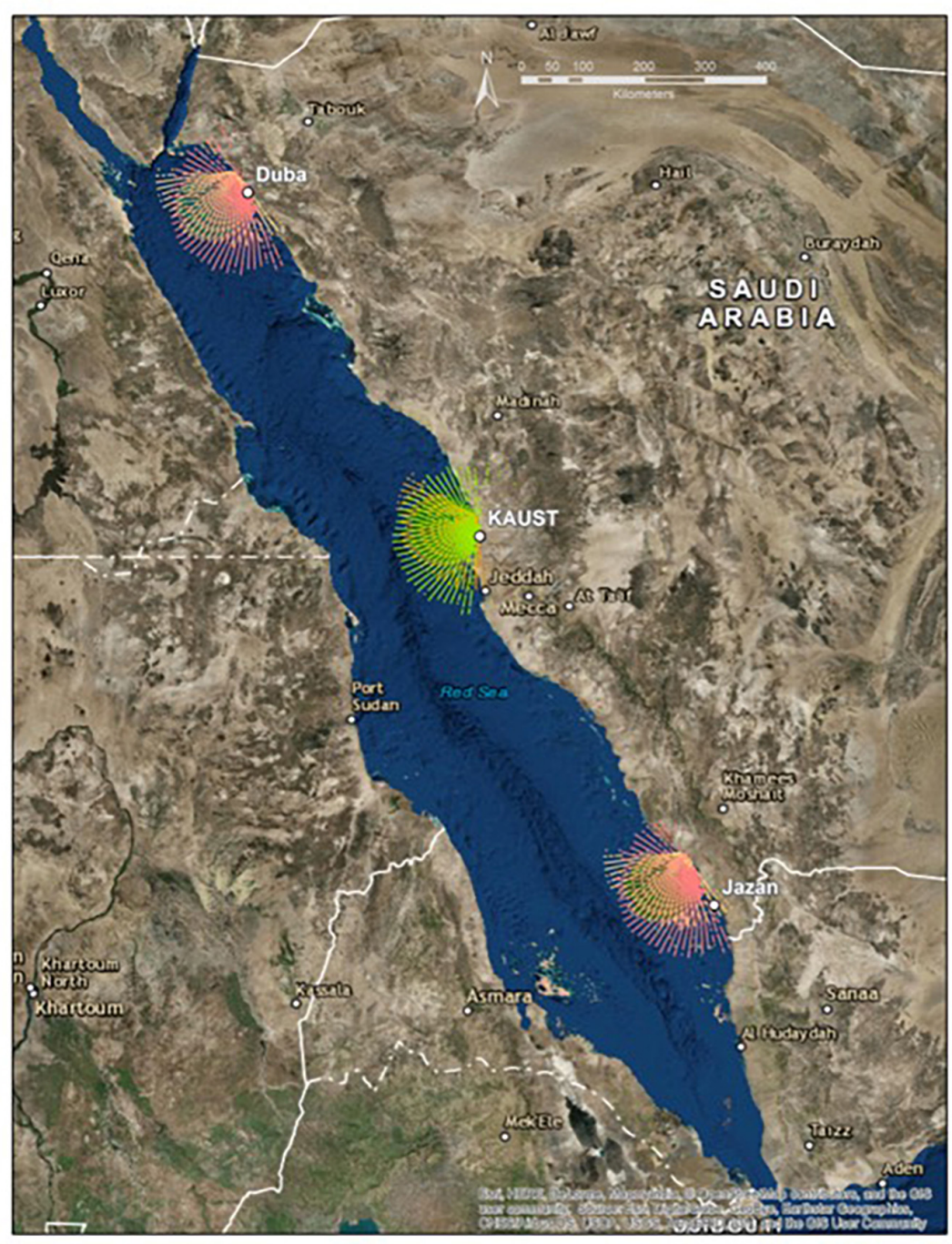

FIGURE 7 | HFR Network off the west coast of Saudi Arabia. The colors indicate typical radial coverage for the 6 HFR stations.

\section{The Americas (Region 2) Canada}

Historically, Canada's coastal HFR activities have focused on vessel detection using phased-array systems on the Atlantic coast (Ponsford et al., 2003). This research and development continues as a component of Canada's defense research programs, but as of 2018 only one of Canada's 22 coastal HFRs falls within this category with an equal number of HFRs on the Pacific and Atlantic coasts. Sixteen of the HFRs are owned by universities and all but three are operated by universities. We make this distinction because the future of coastal HF radar in Canada is influenced by the fact that all of the existing radars and networks are research based and therefore financed through various finite research programs, as opposed to being components of the nation's operational maritime monitoring and surveillance infrastructure.
From an application perspective, vessel detection has the longest track record in Canada, but has yet to emerge from the R\&D stage. Defence Research and Development Canada (DRDC)-Ottawa and Raytheon Canada Limited worked cooperatively for decades to develop over-the-horizon, phasedarray HFR to detect vessels up to $200 \mathrm{~nm}$ from shore. Currently, DRDC Ottawa operates a 3rd generation HFR installed in 2015 near Halifax, Nova Scotia, Canada. The radar includes a spectrum management scheme that allows operation on a noninterference-basis.

Another defense research agency, DRDC Atlantic, is working cooperatively with Dalhousie University and the Marine Environmental Observation Prediction and Response (MEOPAR) Network, with a focus on oceanographic applications. Dalhousie is operating two of DRDC Atlantic's $5 \mathrm{MHz}$ HFRs, which were installed in 2014 near Halifax, Nova Scotia, on either side of the above referenced phased-array 
system owned by DRDC Ottawa. Dalhousie uses surface current data in its coastal circulation and ocean forecasting models. Its Department of Oceanography works cooperatively with Canada's Department of Environment and Climate Change, which is home to the nation's weather forecasting programs and operations. The Atlantic Pilotage Association has also expressed interest in this Halifax R\&D network, but from a wave monitoring perspective in support of ship traffic operations.

On the Pacific coast, Ocean Networks Canada (ONC) (Heesemann et al., 2014) and the Department of Fisheries and Oceans own and operate coastal HFRs at various locations. ONC operates a WERA at Tofino (installed 2016), on Vancouver Island, four CODAR HF radars covering the Strait of Georgia (2011, 2012, 2016), and two CODARs covering Chatham Sound off Prince Rupert $(2016,2017)$. The WERA unit is used by German and American researchers to develop tsunami-detection algorithms. The CODARs are used by research programs run out of the University of British Columbia and the University of Victoria, but also by researchers located in Korea, China and other parts of Canada. There are also two ONC CODARs overlooking the Strait of Juan de Fuca, not fully installed, that await spectral allocation, and the Department of Fisheries and Oceans operates two long-range CODARs on either side of Hecate Strait (installed 2017). The Canadian Coast Guard has expressed interest in using surface current products arising from these and other Canadian HFR.

The longest running coastal HFRs in Canada are owned by the University of Maine, which since 2004 has operated a long-range CODAR in Nova Scotia and another in New Brunswick. Memorial University operates two WERA-like HFRs in Placentia Bay, Newfoundland, and the Université du Québec à Rimouski operates two standard CODARs and a WERA on the St. Lawrence River estuary.

\section{Chile}

Sixteen counties of the Chilean Biobío Region share a border with the ocean, where important sea related economic activities are performed, among them fisheries, navigation, international commerce, infrastructure, defense, tourism, and recreational activities. Historically this region has been affected by natural disasters related to the ocean such as wave surges, heavy weather, tsunami, oil spills, sinking of ships, etc. causing strong social, economic and environmental damages. Several of these risks are associated with physical properties of the coastal waters such as sea waves, surface winds, and marine currents. The solution for these challenges is being answered by the Chilean Integrated Ocean Observing System (CHIOOS). The CHIOOS is based upon two WERA High Frequency (HF) ocean radar systems, which are installed along the coast and provide real-time measurements of physical properties of the coastal waters, and complemented by sensors for relevant biological and chemical ocean parameters. This project will be carried out in strong collaboration with Chilean national and regional agencies, among which are the Chilean Navy National Hydrographic and Oceanographic Service (SHOA), the Chilean Emergency Regional Office (OREMI), the local Maritime Authority (Gobernación Marítima de Talcahuano), the national Ministry of Energy, municipalities of coastal counties, and harbor authorities ${ }^{2}$.

\section{Mexico}

The Mexican HF radar Network has its origin starting in 2003, when the Autonomous University of Baja California (UABC) acquired two SeaSonde CODAR systems, which were operational from 2003 to 2005 on Rosarito Baja California. Later in 2005 another two WERA type radars were purchased through a research project funded by the Concejo Nacional de Ciencia y Tecnologia (CONACyT, National Council of Science and Technology). Those two radars were installed in the Gulf of Tehuantepec, and were operational for almost 3 years (Flores-Vidal et al., 2014).

Those early installations in Mexico had a completely oceanographic research purpose (Flores-Vidal et al., 2011, 2013, 2018) but lacked operational continuity with gaps in the time series on the order of two to 3 months for the worse cases, and with absolutely no real time data transfer. In 2009 the four radars from UABC were installed in Todos Santos bay (100 km south from the United States-Mexico border) and for the first time provided a continuous real-time time series with reduced data gaps due to the ability of data quality control 24/7. The Mexican secretary of Marine corps (SEMAR) used the data during surveillance and SAR operations. In 2010 the Observatorio de Corrientes Mexicanas OCOMEX was created and obtained funding from CONACyT to purchase three more radars which were installed on Baja California producing long-range ( $\sim 200 \mathrm{~km}$ offshore) with time-spatial resolution of $1 \mathrm{~h}$ and $3 \mathrm{~km}$ and real-time support. Up to today OCOMEX is still operational, producing two nested grids of sea surface currents, inside the Todos Santos Bay with resolution of $500 \mathrm{~m}$ and $15 \mathrm{~min}$, and at the adjacent ocean (Southern California Coastal Current) with $3 \mathrm{~km}$ and $1 \mathrm{~h}$ of resolution (Figure 8A). With almost 10 years of measurements with research purposes on the southern California shore (Flores-Vidal et al., 2015, 2018) has brought operational success which supports Mexican federal agencies as well as the academic sector.

In 2015, the Mexican Secretary of Energy (SENER) along with CONACyT launched an unprecedented program for research, surveillance and mitigation in case of oil-spill in the Gulf of Mexico. UABC and OCOMEX were funded to purchase and install 15 radar units on the Gulf of Mexico. OCOMEX decided to install LERA radars (Flament et al., 2016) due to its performance, robustness, compact, and low power consumption design. Presently, the OCOMEX-UABC team operates 16 HFR in the Gulf of Mexico, spanning the states of Tamaulipas, Veracruz, Tabasco, Campeche, and Yucatan (Figure 8B). The installation, management and maintenance of this HFR network is being performed by a multi-institutional consortium which include more than 20 universities and research institutes in Mexico. Currently, OCOMEX operates 22 near real-time (NRT) HFR systems in Mexico and is actively working with United StatesIOOS personnel to establish a relay to the HFRNet.

\footnotetext{
${ }^{2}$ www.chioos.cl
} 

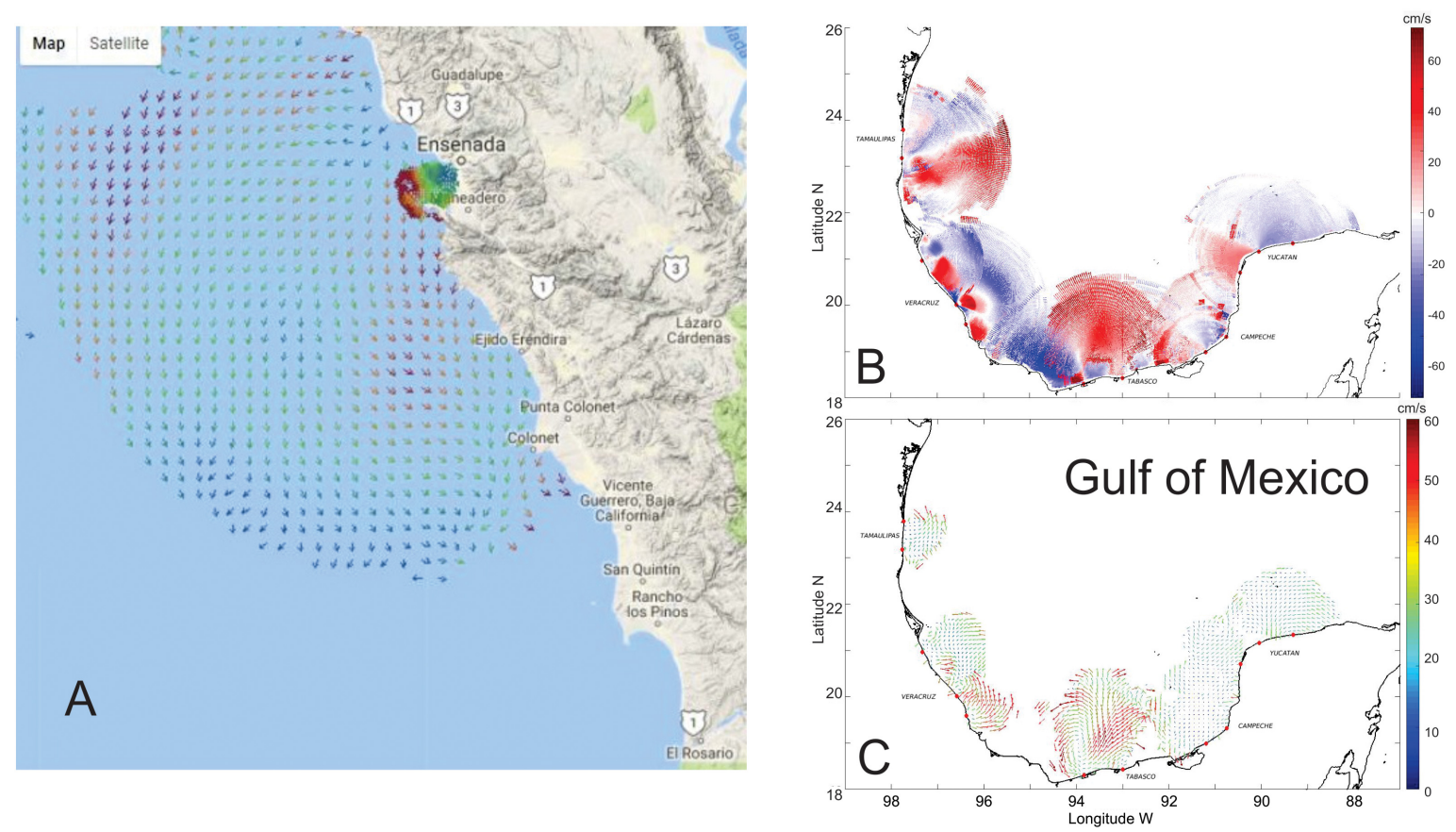

FIGURE 8 | (A) Sea surface currents mapped at high resolution (400 m and $15 \mathrm{~min}$, respectively) inside of Todos Santos Bay, along with long-range (-200 km offshore) measurements simultaneously taken at the adjacent open ocean. Long-range measurements have a time spatially resolution of $3 \mathrm{~km}$ and $1 \mathrm{~h}$, respectively. (B) Map of 11 radar stations (red dots) installed in the Gulf of Mexico from 2017 to 2018 showing radial currents toward the radar station (red) and away from the radar station (blue) (C) the radial measurements from (B) are combined to generate total vector currents between 0-50 cm/s.

\section{United States}

In 2004 the United States led Integrated Ocean Observing System (IOOS) established a national network of HFR sites along the coastal United States, frequently referred to as the National Network (Harlan et al., 2010). The National Network differentiates sites by geographical area including the United States West Coast (USWC), United States East and Gulf Coast (USEGC), Hawaii (USHI), and Puerto Rico and Virgin Islands (PRVI). Additionally, when weather conditions allow (typically during summer months), HFR sites from Alaska North Shelf (AKNS) and Gulf of Alaska (GAK) are included. The technical basis of the National HFR Network was guided by a steering team of experts in the field, with the resulting documentation distilled into a National Surface Current Plan (U.S. Integrated Ocean Observing System [IOOS], 2015) which has been updated occasionally since its initial publication. The plan describes the design and implementation of the National HFR Network from the infrastructure of individual HFR stations, data management and dissemination, and HFR related product development. The report highlights the requirement to collect surface current given its societal importance, and established priority for the location of HFR stations within eleven regional associations (RAs) which guide development of regional ocean observing activities. Furthermore, the plan provides technical design of the National Network to acquire radial current maps from individual HFR stations, process the radial maps into a Real Time Vector (RTV) product and establish requirements for data standards, management and distribution, while providing a metric of performance which is monitored daily. The report also recognized the importance of staffing structure through academia/federal partnerships.

The HFR National Network began collecting radial current maps from participating regions in 2006 (Figure 9). The geographic coverage for each region over the entire period of recording is shown for the main regions. Surface currents collected through IOOS HFR National Network are utilized by a number of federal agencies including United States Coast Guard (Search and Rescue), NOAA's Office of Response and Restoration (OR\&R) (hazardous spill response), National Ocean Service Center for Operational Oceanographic Products and Services (CO-OPS) (ocean tidal prediction), as well as state and local agencies that use data in water quality management. Additionally, surface current data is distributed to various research and development groups that are assimilating HFR derived surface current into numerical models. The United States West Coast Ocean Forecast System (WCOFS) is developing a capability to assimilate HFR surface currents into the $2-\mathrm{km}$ horizontal resolution, ROMS based numerical model run along the entire United States West Coast (Kurapov et al., 2017). Finally, the IOOS-funded Short-term Prediction System (STPS) uses realtime analysis of the HFR surface currents to predict trajectories that are fed to the United States Coast Guard SAR tools (Roarty et al., 2010; Harlan et al., 2015).

\section{Asia and Oceania (Region 3)}

The status for HFR for Australia, China, Japan, Korea, and Taiwan was documented recently (Fujii et al., 2013). Here are recent advancements for some of these countries as 


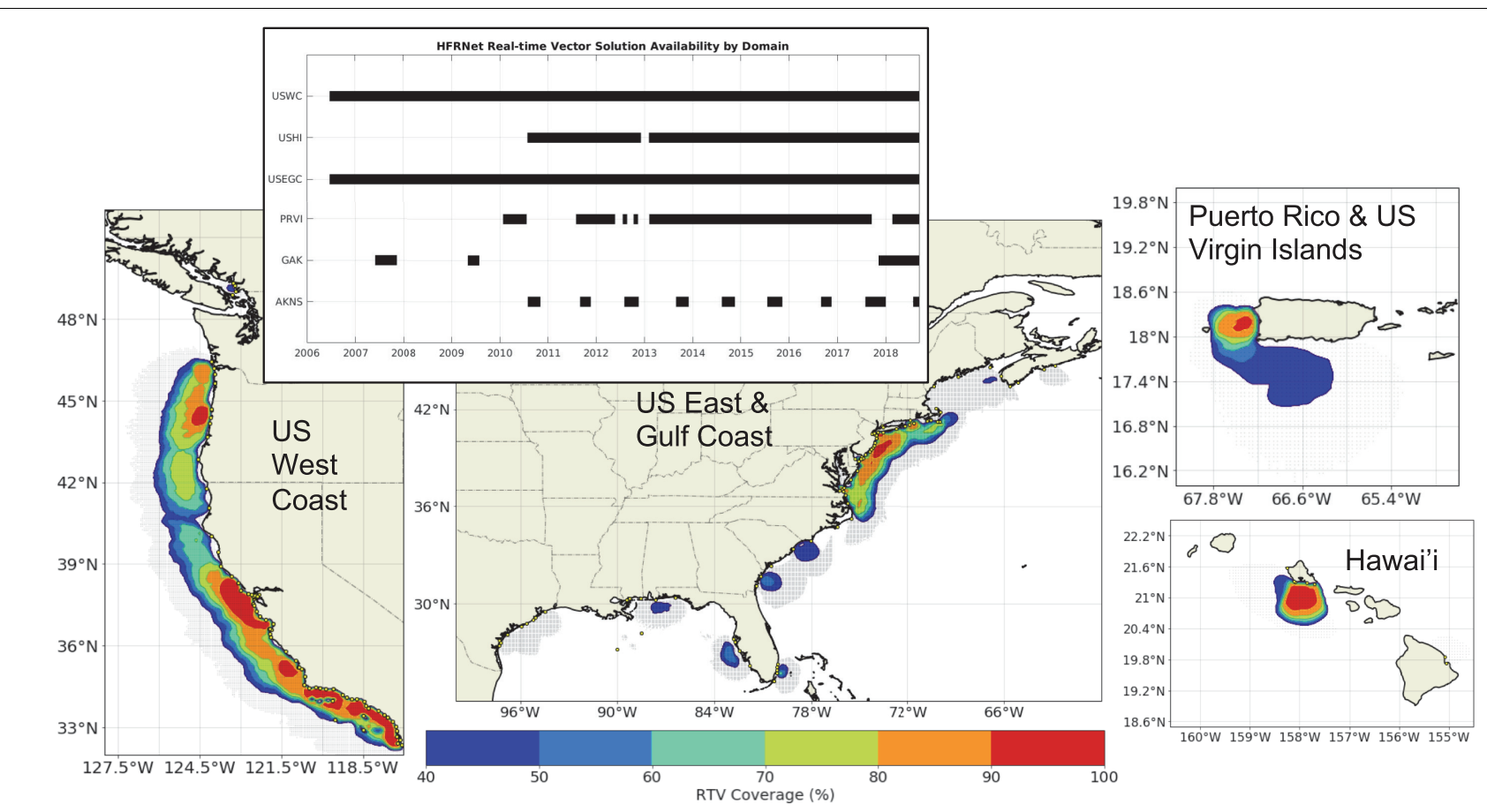

FIGURE 9 | Temporal and spatial coverage of United States IOOS HFR National Network by region since 2006.

well as a description of HFR in the recent networks of Vietnam and Thailand.

\section{Australia}

The Australian Ocean Radar facility, based at the University of Western Australia is part of the Integrated Marine Observing System (IMOS), a national collaborative research infrastructure tasked with collection and dissemination of ocean data. The radar facility uses commercial direction-finding (SeaSonde) and phased-array (WERA) HFR systems. Each HFR node is configured primarily to sample ocean currents with a maximum range of over $200 \mathrm{~km}$. Radar data, freely available from the IMOS portal $^{3}$, are used for scientific research, operational modeling, coastal monitoring, fisheries and other applications (Kerry et al., 2016; Mihanovic et al., 2016; Archer et al., 2017, 2018; Mantovanelli et al., 2017; Schaeffer et al., 2017; Wandres et al., 2017). Between 2017 and 2018 asset relocation across the country was conducted, aimed at maximizing HFR coverage at a regional scale, and increasing data uptake. A new regional node was added to the network north of Sydney (New South Wales) composed of long-range ( $5 \mathrm{MHz}$ ) SeaSonde HFR systems, became operational in December 2017 but soon caused interference problems to primary users and has since been operated below its capabilities. The transmit power was reduced, typically below 1 Watt and sweep width reduced to less than $50 \%$ of the ITU allocated bandwidth, yet these settings were still causing interference to several users across the country. To date, operational uptime at this location is less than $50 \%$. The spectrum management agency

${ }^{3}$ https://portal.aodn.org.au/ within Australia (ACMA) is now enforcing a full implementation of ITU resolution 612 before operations can be resumed at this location. These requirements now include use of a directive transmit antenna, reduced bandwidth and employing a technique to allow multiple radars to operate on the same frequency. In 2018, the Federal Government approved operations for the 2018-2022 time period with potential to continue operation for additional 5 years, providing operational budget and injection of significant funds for the refurbishment and upgrade of the entire HFR systems, and replacement of the aging infrastructure. Additionally, the relocation of a decommissioned phased array HFR node from Queensland to the northwest shelf of Western Australia was approved through co-investment between IMOS and the oil and gas industries in the area, in support to development of an ocean monitoring tool for the Ningaloo reef, a world heritage area.

\section{Vietnam}

Analysis of the spatial and temporal ocean circulation patterns of the Gulf of Tonkin are the focus of an ongoing collaborative effort between the Vietnamese Center for Oceanography (CFO), Vietnam Administration for Seas and Islands (VASI), and United States partners. Three long-range HF radar sites were installed in the spring of 2012 within the Gulf of Tonkin, Vietnam (Figure 10A). The temporal availability and spatial coverage of the radial data were strongly dependent on the seasonal monsoon cycles that drive observed circulation patterns within the predominantly low energy environment of the Gulf of Tonkin. Minimal radial coverage occurred during the summer monsoon seasons due to prevailing weak offshore wind directions. The 

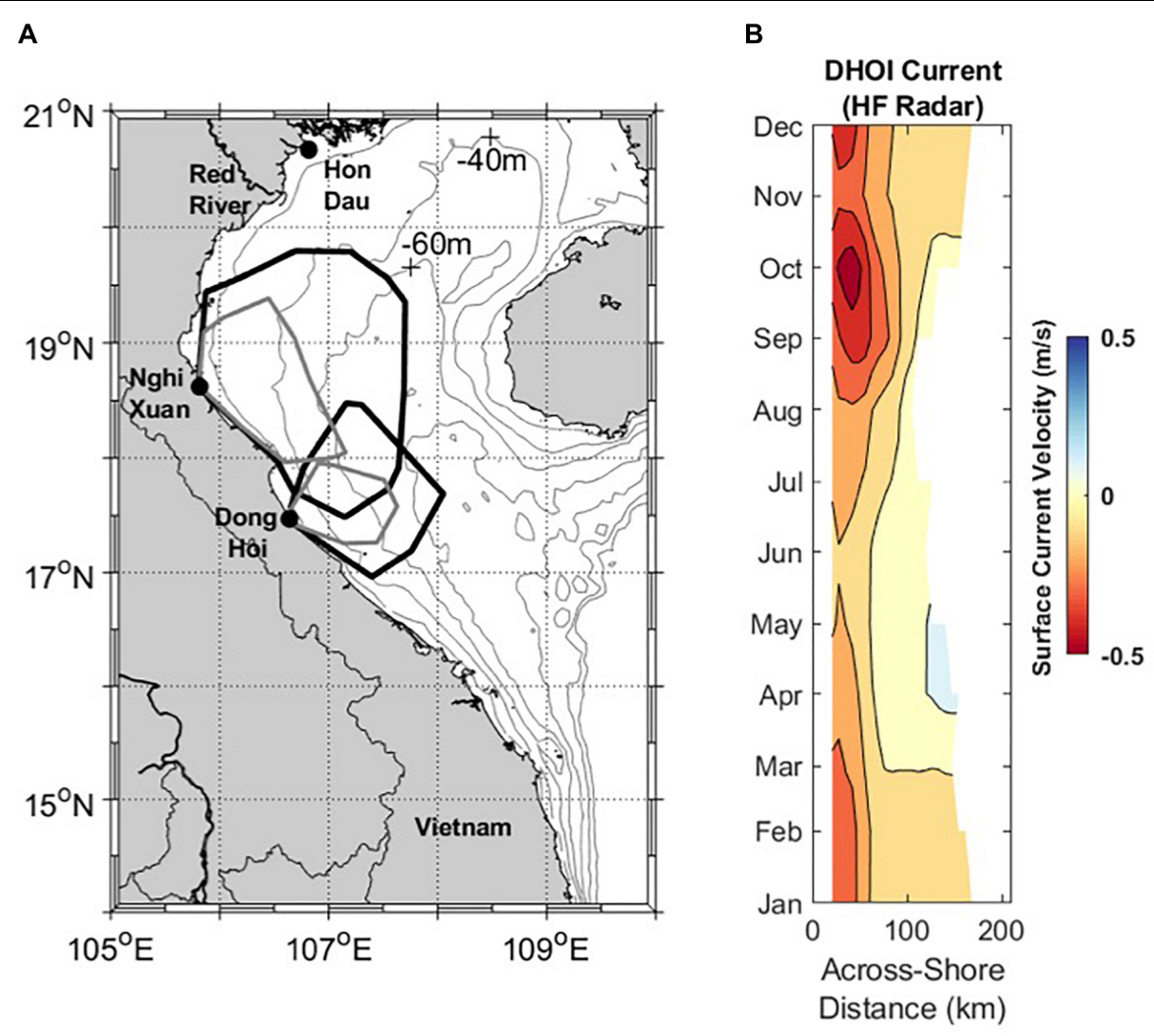

FIGURE 10 | (A) Map of Vietnamese coastal waters with HFR stations (black dots) overlaid with $20 \mathrm{~m}$ depth contours. The polygons indicate the $50 \%$ radial data coverage boundaries of the HF-radar during the winter season (black line) and summer season (gray line). (B) Hovmoller diagrams of HF radar alongshore surface currents located just north of the Dong Hoi radar site. Positive currents indicate poleward flow while negative values denote regions of equatorward flow. HF radar monthly averages are computed from a 2 year period from June 2014 to June 2016.

onset of the winter monsoon season results in a transition to an onshore flow resulting in better temporal availability and spatial coverage of radial data (Figure 10A).

Numerical simulations confirm coastal flows, originating from the Red River, are a prominent feature impacting the circulation of the western region of the Gulf of Tonkin. Two years of monthly averaged HF radar observations, from June 2014 through July 2016, were used to assess the seasonal temporal and spatial variability of coastal currents. The upcoast/downcoast surface currents along a shore normal $200 \mathrm{~km}$ transect just north of the Dong Hoi radar site for this period illustrates seasonal fluctuations in the coastal current that are consistent with model results (Figure 10B).

As a result of the successes from the United States Vietnamese partnership, future efforts will build on the developed relationships to continue education and training in the use of emergent ocean technologies. This will include working with VASI and CFO as they begin to further develop their HF radar infrastructure along the Vietnamese coast.

\section{Korea}

As Korean economy has increased, the importance of NRT surface currents measured in coastal and marginal seas around Korea has been recognized since 1995. Pukyoung National
University (PNU) first installed HFR systems in the southeast coast in 1999 to monitor the East Korea Warm Current (EKWC). HFR systems gradually increased with oceanographic demands for 10 years (Figure 11B). The HFR network rapidly expanded from 9 radar sites in 2009 to 46 sites in 2016 in order to respond to increasing demands of the current data covering large areas with increased spatial and temporal resolution for fishing activities, maritime transportations, coastal zone developments and harbor constructions, and coastal environment managements.

The Korea Hydrographic and Oceanographic Administration (KHOA) has been focused on operational application of radarderived currents around six major harbors with 31 HFRs where ship traffic is heavy, providing NRT data to the public and wide variety of end-users. Universities and research institutes have mainly applied HFR systems to scientific researches. Kunsan National University (KNU) has installed radars to examine the effects of large coastal development on the current structure and variation of river plumes (Son et al., 2007; Lee et al., 2013; Kim et al., 2018) and the observation-based current variabilities for the effective management and utilization of the mid-west coastal sea in the future. Seoul National University (SNU) has operated HFRs to map surface current along the mid-east coast where the East Korea Warm Current (EKWC) and North Korea Cold Current (NKCC) meet and frequently produce complicated 

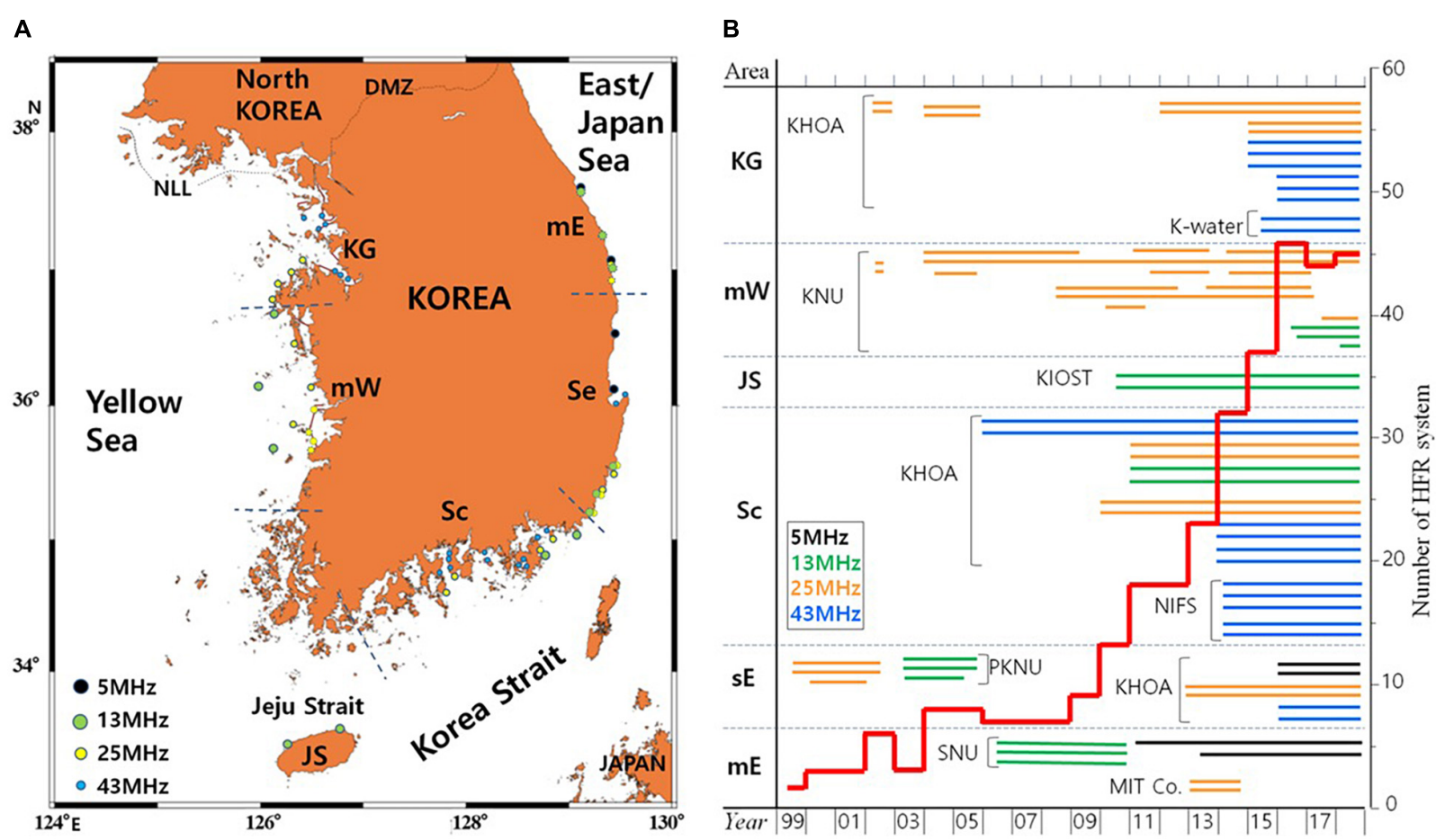

FIGURE 11 | (A) Locations HFR sites observing surface current around Korean coast that is divided into 6 areas with abbreviated coast-name, KG, Kyug-Gi bay; mW, mid-west coast; JS, Jeju Strait; Sc, South coast; Se, south east coast; mE, mid-east coast. Circles with dotted line denote the closed sites. (B) Number of radar sites operated by Korean organizations from 1999 to 2018 (bold red line). Capital characters indicate the abbreviated name of HFR operating organizations (see the text for full name).

flow patterns. Korea Institute of Ocean Science and Technology (KIOST) has operated two radars $(13 \mathrm{MHz})$ since 2012 to observe the current structure and variability in the Jeju Strait. National Institute of Fisheries Science (NIFS) has operated an HFR network since 2014 to investigate the dispersion and residence time of pollutant materials in the inner bays along the south coast in order to plan the sanitation management and space requirements for aquaculture farms. Korea Water Resources Corporation (K-water) has monitored the outflow jet from the gate of Shihwa lake tidal power station to estimate effects of the jet flow on the coastal environment since 2015. Marine Information Technology Co. (MIT) has mapped currents and waves off the mid-east coast from 2013 to 2014 for a meteorological demand using the two HFRs that are a unique WERA system in Korea.

With the increase of HFR systems, the Korean HFR community recognized the necessity of cooperation between organizations to share experiences and information about radar operation and promote the efficient use of radar-derived data. The Korean Ocean Radar Forum (KORF) was established in 2011 for this purpose. KORF holds a workshop every year, and discusses issues that are common to operators and endusers in Korea. In May 2012, KORF organized the 1st Ocean Radar Conference for Asia-Pacific (ORCA) in Seoul Korea to share experiences on HFR network planning, operation, maintenance and data management, exchange ideas about application and research results, and build relationships across national boundaries (Lee and Heron, 2013; Fujii et al., 2013).
More than seventy persons from ten countries participated in the 1st ORCA and the conference has been successively held every 2 years.

Though 45 HFRs are presently operating in the Korean coast for public and scientific usages, partnership between KORF members has not established yet to organize a nation-wide data node to systematically respond to a wide array of end user's demands. Recently the Korean government recognized HFR as a valuable platform for building wide integrated surveillance of marine territory and launched a research project integrating satellite, AIS, HFR, UAV etc. data and platforms. The Korean HFR community is trying to establish a national organization to collect HFR-data to a data aggregation node, support technical and operational design for data standards, management and distribution, raise funds for a national network installation, and participate to the international observing programs over the next decade.

\section{Thailand}

Thailand first began installing HFR systems in 2012 and are operated under the responsibility of Geo-Informatics and Space Technology Development Agency (GISTDA), which is located within the Ministry of Science and Technology. The purpose of the project is to understand the circulation pattern and wave characteristic in the Gulf of Thailand in both time and space continually in order to support the government's water management system from land into the coastal zone. The coastal 
radar systems in Thailand use frequencies of 13 and $24 \mathrm{MHz}$ covering the Gulf of Thailand and Andaman with a total of 19 stations. Installing the system was divided into two phases, consisting of the first phase from 2012 to 2015 which installed 13 stations in the Gulf of Thailand and the second phase from 2016 to 2018 which installed 4 stations in the Gulf of Thailand and 2 stations in the Andaman Sea. The HFR platforms in Thailand have also been outfitted with closed circuit television for displaying of wave and weather conditions to the public.

Geo-Informatics and Space Technology Development Agency has developed geographic information systems that integrate satellite imagery, coastal radar surface currents and other related remote sensor to monitor marine and coastal environments in the Gulf of Thailand and Andaman sea. This integrated product is paired with a vessel tracking system to analyze marine pollution by modeling the pollution situation and direction. These data are used as a tool for analyzing pollution sources, planning and situation management, including marine pollution alerts from oil spills or phytoplankton blooms. The HFR data is also utilized for monitoring waves and currents which are the factors affecting coastal zone change in Thailand, as well as for integrating approaches, project plans and budgets for coastal erosion management. Lastly, integration of coastal radar data with satellite imagery data and other information such as sea temperature and chlorophyll content for is helping fisheries management, water quality monitoring and marine resource conservation in Thailand.

Information from coastal radar systems has been used by government agencies, educational institutions, the private sector and the general public by accessing to the data via web-based applications and mobile applications. The development of coastal radar systems in Thailand under the implementation of GISTDA is another useful remote sensor for coastal area management. The application of this technology not only fulfills the mission of GISTDA, but it is a response to the mission of all marine and coastal sectors in Thailand. The use of such systems is diverse and focuses on the overall strategy of the country. Based on our past performance, lowering system maintenance costs is very important and future plans, we will continue to focus on the development of systems based on the integration of GISTDA and partner agencies expertise in geospatial information systems (GIS, satellite imagery, GNSS, remote sensors) to enhance capability of the people and coastal communities to utilize and access this information in order to improve the quality of life and safety in our coastal waters.

\section{Taiwan}

Taiwan is an island on the margin sea between the western Pacific and the Eurasian shed. The interaction between the ocean and the residents is very close. The first set of HFRs introduced in Taiwan can be traced back to the 1990s. The Naval Meteorological and Oceanographic unit was responsible for operating the HFR system. They were expected to provide over-the-horizon ocean surface currents and wave information for the battlefield. Later, at the initiative of ocean scientists and disaster prevention experts, government departments such as science and technology, education and transportation systems launched projects for the construction of High Frequency surface wave radars for ocean monitoring beginning around 2010. As of 2018, includes: 19 HFRs are operated by TOROS (the research organization for the establishment and maintenance of marine radars within the Taiwan Ocean Research Institute), two HFRs operated by the Naval Academy (called SCONET) and the two phased array radars operated by the Harbor and Marine Technology Center. Over the past 8 years these radar systems have provided continuous, NRT surface current maps of the surrounding waters around Taiwan and sea state information for the 14 commercial harbors and 225 fishing ports. The HFRs have played an important role in marine environmental information for coastal ocean science research, navigation or recreational safety, and maritime SAR.

Therefore, starting in 2019, the Central Weather Bureau of the Ministry of Transportation and Communications will construct an observation network consisting of three phased array radars in the northern Taiwan Strait to provide metocean information needed for transportation safety. The Harbor and Marine Technology Center will also implement a phased array radar in central Taiwan to monitor the sea state and vessel status within an offshore wind farm. Another network being developed entails monitoring the Luzon Strait between Taiwan and the Philippines which will form the Luzon Strait Ocean Observation System (LuSOOS).

\section{DATA PRODUCTS, QUALITY CONTROL, AND DISSEMINATION}

\section{Deployment and Maintenance Best Practices}

Given the need to collect high-quality observations from a number of independent organizations at varied coastal locations, IOOS has supported HFR technical and operation staff under the Radiowave Operators Working Group (ROWG). Founded in 2005 this group maintains an informational wiki $^{4}$ (password protected), email list, and computer code repository ${ }^{5}$. The group is open to HFR operators from the United States and international institutions and meets frequently to discuss standard practices, maintenance concerns and technology updates. The group has encapsulated best practices for HFR equipment setup and required maintenance into a living document called Deployment \& Maintenance of a High-Frequency Radar for Ocean Surface Current Mapping: Best Practices (Cook et al., 2008). Topics include site setup of HFR equipment, power and cooling considerations, software/hardware configuration, data management and site maintenance. Additionally, HFR vendors provide guidance to HFR operators to assist with the goal of collecting the highest quality data as different locations may have specific issues and concerns and there is no "one size fits all" approach to HFR site deployment.

\footnotetext{
${ }^{4}$ http://rowg.org

${ }^{5}$ http://github.com/rowg
} 
In Europe, the EuroGOOS HF Radar Task Team was established in 2014, with the goals of: (i) promoting joint progress through networking and scientific synergies for key questions; (ii) developing best practices and tools exchange; (iii) improving administrative procedures and regulations (e.g., the cross-border agreement for oceanographic radars in the 13$16 \mathrm{MHz}$ band operating in the Western Mediterranean Sea in Spain, France and Italy was signed in February 2018); (iv) looking for complementary of HFRs with other multi-platforms and model products ${ }^{6}$. Simultaneously, definition of best practices in the implementation and use of HFR systems as well as the testing of methodological improvements on HFR retrievals and products is reported in the context of JERICO-NEXT project.

Dealing with one of the main risks foreseen in order to ensure HFR sites sustainability (i.e., downtime, outages and failures), the EU HFR data node, aligned with the leading efforts of MARACOOS, have shared best practices for the creation of HF Radar outages database (Updyke, 2017) as an aid for operations and maintenance. In spite of the fruitful collaborations between the HFR national networks, operators recognized the necessity for a centralization of methodologies and best practices documentation to increase efficiency, reproducibility and interoperability of the coastal HFRs network design, operation and maintenance tasks, In this context, the Ocean Best Practices (OBP) System ${ }^{7}$ is emerging as the unified, sustained and readily global accessible knowledge based of interdisciplinary best practices in the ocean observing value chain to foster innovation and excellence. Particularly, in the case of HFR, best practices documentation related to the EU network current status, QA/QC HFR surface current data, deployment \& setup of HFRs and HFR data management are currently available at the IODE OBP repository ${ }^{8}$. Nevertheless, an extra effort is required from the global HFR network to document best practices and to promote their propagation. Moreover, the involvement of HFR experts from different networks may contribute to the internal peer-review of best practices documents.

\section{Quality Assurance/Quality Control}

Within the United States, IOOS strives to collect the highquality data for 34 identified core variables, which include ocean currents. To this goal, the Quality Assurance/Quality Control (QA/QC) of Real-Time Oceanographic Data (QARTOD) Project Plan was finalized in 2012, and established quality control procedures for the 26 core variables representing physical, chemical, biological, and multidisciplinary ocean observations (U.S. Integrated Ocean Observing System [IOOS], 2017). Coordinated effort between manufacturers, academic researchers and federal scientists created the Manual for RealTime Quality Control of High Frequency Radar Surface Current Data published in 2016 (U.S. Integrated Ocean Observing System [IOOS], 2016). The manual incorporates existing QA/QC procedures from a group of HFR experts, and identified a number of tests to ensure QA/QC of both radial current

\footnotetext{
${ }^{6} \mathrm{http}: / /$ eurogoos.eu/download/Task-Team-updates-GA2016.pdf

${ }^{7}$ https://www.oceanbestpractices.org

${ }^{8}$ https://www.oceanbestpractices.net
}

measurement and total current vector measurement. Efforts to implement these tests in the real time data stream are ongoing and occurring at the radial current collection sites, and at the National Network.

In order to deliver high quality HFR data for scientific, operational and societal applications and to enforce discovery and access for HFR data, the European HFR community defined a standard model for data and metadata for producing NRT HFR surface current data, aimed at ensuring efficient and automated HFR data discovery and interoperability. This data model will be the operational data delivery model since the entry in service of HFR data distribution in CMEMS-INSTAC occurs in April 2019. The model has been implemented according to the standards of Open Geospatial Consortium (OGC) for access and delivery of geospatial data, and compliant with the Climate and Forecast Metadata Convention CF-1.6, to the Unidata NetCDF Attribute Convention for Data Discovery (ACDD), to the OceanSITES convention and to the INSPIRE directive. Furthermore, it has been defined following the guidelines of the DATAMEQ working group and it fulfills the recommendations given by ROWG. To enforce semantics and interoperability, controlled vocabularies are used in the model for variable short names and standard names. All the discussions and activities for the data model definition and implementation have been carried on in strict collaboration with the US colleagues through ROWG. Other important external contributions have been given by other networks, such as the Australian ACORN network. Moreover, representatives of all these groups meet periodically at ROWG and ROW meetings, Ocean Radar Conference for Asia Pacific (ORCA) meetings and there was one ad-hoc meeting (INCREASE HFR expert workshop La Spezia 2016).

The model specifies the file format (i.e., netCDF-4 classic model), the global attribute scheme, the dimensions, the coordinate, data and Quality Control (QC) variables and their syntax, the QC procedures and the flagging policy for both radial and total data (Corgnati et al., 2018b). A battery of mandatory QC tests to be performed on NRT HFR data has also been defined, in order to ensure the delivery of high-quality data, to describe in a quantitative way the accuracy of the physical information and to detect suspicious or unreliable data. These QC tests standard model to be applied to HFR radial (7 tests) and total (6 tests) data were defined according to the DATAMEQ working recommendations on real-time QC and building on the QA/QC of Real-Time Oceanographic Data (QARTOD) manual produced by the United States IOOS (Corgnati et al., 2018b).

The QC standard model will be the operational standard data model starting with delivery of HFR data distribution in CMEMS-INSTAC in April 2019. Until recently, the implementation of real time QA/QC procedures of the data was depending on the HFR operator experience level. NRT validation of the HFR surface currents against surface currents of point-wise current meters or from ADCPs located inside the HFR footprint area provides a systematic data evaluation, helping also to identify periods without data (e.g., no radial velocities produced by the site, hardware/software outage, power outage, communication lost) or periods of instrument malfunction (e.g., either from the radar or from the other instruments) when velocities suddenly appear unrealistic. Of course, the 
NRT validation should not substitute the traditional offline validation practices (performed at delayed-mode system), but it complements it. The most common delayed-mode validation of HFR currents performed so far are based on comparison with drifter trajectories and point-wise current meters and ADCPs located in the HFR footprint along with self-consistency checks at the midpoint of the overwater baseline (Lorente et al., 2014; Kalampokis et al., 2016; Corgnati et al., 2018a; Cosoli et al., 2018). Equally, a variety of validation exercises of HFR-derived wave measurements against in situ observations have been previously conducted (Atan et al., 2015; Gómez et al., 2015) in order to infer the accuracy of HFR remote-sensed estimations and quantify the uncertainties related to this technology.

\section{Open Source Software Tools}

One benefit of organizing the network globally are the resources that can be shared across all networks. Free and open-source software packages available for managing and analyzing HFR data have been developed. A sampling of the open source tools are described in Table 2 including its functionality, the link to the repository and the primary authors of the tools. Constant knowledge sharing on the existing software and further updates will bring continued benefits to the global network participants. By sharing these tools as a community new features and benefits can be developed faster and more effectively than internal teams. The use of open source code should be promoted to gain full visibility and to increase reliability with the HFR worldwide community supporting the code base.

\section{Data Access and Visualization}

Within the United States, the HFR National Network data management system relies on robust communications between the individual HFR installations and centralized data repositories that are updated in NRT. Radial surface currents are measured hourly at HFR installations (a site) and synced with one of 9 local regional operations centers (a portal) that aggregate radial current data from all HFR sites within a RA. In turn, data from the portals are accumulated at two redundant data repositories (a node) which are housed at Scripps Institution of Oceanography (SIO) and the National Data Buoy Center (NDBC). The primary node, located at SIO, serves the hourly radial current files to HFRNet processing machines which produce near real-time total vector (RTV) product generated on grids with multiple resolutions $(500 \mathrm{~m}, 1,2$, and $6 \mathrm{~km})$. Distribution of the RTV and 25-hr average products is accomplished through a Thematic Real-time Environmental Distributed Data Services (THREDDS) server ${ }^{9}$. THREDDS provides an interface to data access using a number of open source protocols including OpenDap, Web Mapping Service (WMS), Web Coverage Service (WCS), NetCDF Subset, and others. Sample code is available for utilizing these services with popular data processing platforms such as MATLAB and Python/Matplotlib. Vector tiles of all RTV products are available to web mapping applications via a publicly accessible application programming interface ${ }^{10}$.

\footnotetext{
${ }^{9}$ http://hfrnet-tds.ucsd.edu/thredds

${ }^{10} \mathrm{http}: / /$ cordc.ucsd.edu/projects/mapping/api/
}

In addition to RTV products, the diagnostic information included in the HFR radial files is stored in a database and displayed to site operators through the HFRNet diagnostics portal. Diagnostic information includes hardware specific data such as system voltages, transmitted and reflected power and radial vector data such as range, number of solutions and signal to noise ratio.

Finally, overall IOOS network performance is evaluated using diagnostics from individual sites contributing to HFRNet through a real-time metric that is reported to the IOOS program manager and site operators. This metric categorizes when a radial file passes certain criteria, which are based on long term statistics of similar sites within the HFRNet archive. These criteria include the arrival time of a radial file (file must be received at HFRNet within $24 \mathrm{~h}$ of its collection) and the number of solutions (the number of valid radial solutions in the file must exceed a baseline).

In addition to THREDDS for both NRT and delayed mode (DM) products, the Australian Ocean Data Network (AODN) is making publicly available aggregated HFR data through their portal ${ }^{11}$. This includes surface currents, wind and wave maps. Within Europe the major platform for marine data distribution are CMEMS-INSTAC and the SeaDataNet infrastructure (SDN/SDC). They operate through a decentralized architecture based on National Oceanographic Data Centers (NODC) Production Units (PUs) organized by region for the global ocean and the six European seas and a Global Distribution Unit (DU). The core of CMEMS-INSTAC and SDC is to guarantee for the users the quality of the product delivered is equivalent wherever the data are processed.

In this framework, in order to enforce and make operational the efficient management of HFR data for INSTAC PUs, other CMEMS Thematic Centers (TAC) and Marine Forecasting Centers (MFC), the establishment of the HFR data stream has to be organized in a coordinated way, in collaboration with the regional alliances of EuroGOOS and the regional and global components of the CMEMS In Situ TAC. The implementation of the HFR data stream will be operated by a centralized European competence center: the EU HFR Node. This implementation will be performed in the frame of CMEMS In Situ TAC with the established formats and standards on QC flags and tests, dimension, naming, definition and syntax of coordinated variables.

The EU HFR Node will act as focal point with the European HFR data providers, the key EU networking infrastructures and the Global HFR network. The key roles of the EU HFR Node will be the connection with data providers for NRT and reprocessed (REP) data, the connection with CMEMS-INSTAC for NRT and REP data, the connection with SeaDataNet for REP data. The node will also ensure optimal visibility of HF radar data and foster the applications based on HF radar data. The EU HFR Node will facilitate the management and integration of any potential data provider according to a simple and very effective rule: if the data provider can set up the total surface current data flow according to the defined standards, the HFR central node only has to link

\footnotetext{
${ }^{11}$ https://portal.aodn.org.au/
} 
TABLE 2 | Summary of open source software toolboxes for the processing and visualization of HFR surface current data.

\begin{tabular}{|c|c|c|c|}
\hline Toolbox & Functionality & Programming Language & Primary Author/Link \\
\hline HFR_Progs & $\begin{array}{l}\text { Total currents generation, Open -boundary Modal } \\
\text { Analysis, Interpolation and filtering, Tides, EOFs }\end{array}$ & MATLAB & $\begin{array}{l}\text { Mike Cook, Naval Postgraduate School David } \\
\text { Kaplan, Virginia Institute of Marine Science } \\
\text { https://github.com/rowg/hfrprogs }\end{array}$ \\
\hline \multirow[t]{2}{*}{ Codar Processing } & $\begin{array}{l}\text { Python tools for working with radial and wave data. } \\
\text { Loading ASCII data files, QC, exporting to NetCDF }\end{array}$ & Python Jupyter Notebook & Michael Smith, Rutgers University \\
\hline & & & https://github.com/rowg/codar_processing \\
\hline \multirow[t]{2}{*}{ Hfr_gui } & $\begin{array}{l}\text { Graphical user interface (GUI) for processing and } \\
\text { visualizing HFR data }\end{array}$ & MATLAB & Teresa Updyke, Old Dominion University \\
\hline & & & https://github.com/rowg/hfr_gui \\
\hline \multirow[t]{2}{*}{ JRADAR } & $\begin{array}{l}\text { Transformation of CODAR radial and total files into the } \\
\text { European HFR data model }\end{array}$ & Java & Jose Luis Asensio, AZTI \\
\hline & & & https://github.com/llasensio/JRadar \\
\hline \multirow[t]{2}{*}{ HFR_Combiner } & $\begin{array}{l}\text { Standard QC processing and combination of CODAR } \\
\text { and WERA radial current into total current and } \\
\text { generation of radial and total data into the European } \\
\text { HFR data model. }\end{array}$ & MATLAB & $\begin{array}{l}\text { Lorenzo Corgnati and Carlo Mantovani, } \\
\text { CNR-ISMAR }\end{array}$ \\
\hline & & & $\begin{array}{l}\text { https://github.com/LorenzoCorgnati/HFR_ } \\
\text { Node_tools }\end{array}$ \\
\hline \multirow[t]{2}{*}{ Total Conversion } & $\begin{array}{l}\text { Standard QC processing and transformation of Codar } \\
\text { and WERA total current into the European HFR } \\
\text { common data \& metadata model }\end{array}$ & MATLAB & $\begin{array}{l}\text { Lorenzo Corgnati and Carlo Mantovani, } \\
\text { CNR-ISMAR }\end{array}$ \\
\hline & & & $\begin{array}{l}\text { https://github.com/LorenzoCorsnati/HFR_ } \\
\text { Node_tools }\end{array}$ \\
\hline \multirow[t]{2}{*}{ HFRadarReports } & $\begin{array}{l}\text { Automatic generation of monthly reports, as a new } \\
\text { product for HFR data quality assessment }\end{array}$ & Python and La Tex & $\begin{array}{l}\text { Andreas Krietmayer, Charles Troupin, Grant } \\
\text { Rogers and Emma Reyes, SOCIB }\end{array}$ \\
\hline & & & https://github.com/socib/HFRadarReports \\
\hline
\end{tabular}

The table shows the name of the toolbox, its main features, the programming language it was written in, the author and URL to the GitHub repository.

and include the new catalog and data stream. If the data provider cannot setup the total data generation and flow (because of lack of experience, technical capacity, etc.), the HFR Node will work on harvesting the radial data from the provider, harmonize and format these data and make them available.

For all these reasons the establishment of a centralized HFR node is the cornerstone of the operational European HFR network. The EU HFR Node became pre-operational in November 2018 and fully operational in April 2019 for CMEMS-INSTAC and SDN/SDC data delivery. It is also designed to maximize the compatibility and the possibility of mutual integration with the United States HFRNet. Links to data access portals for each of the regions are given in Table 3 .

\section{APPLICATIONS}

\section{Search and Rescue}

Public Agencies and private companies in charge of SAR missions, marine pollution response, and maritime traffic control are among the most significant targeted users of reliable surface currents. It is essential for NRT surface currents be reliable and current predictions be accurate for the specific marine SAR areas of responsibility as assigned by the IMO (International Maritime Organization).

HFR data and predictions are one important part of SAR in the United States, being used as operational input
TABLE 3 | Website links to the portal for the global network along with links for data access in each of the three regions.

\begin{tabular}{ll}
\hline & Link to data \\
\hline Global Network & http://global-hfradar.org/index.html \\
Region 1 & http://thredds.emodnet-physics.eu/thredds/ \\
& HFRADARCatalog.html \\
Region 2 & http://hfrnet-tds.ucsd.edu/thredds/catalog.html \\
Region 3 & https://portal.aodn.org.au/ \\
& http://www.khoa.go.kr/koofs/kor/ports/
\end{tabular}

to United States Coast Guard Search and Rescue Optimal Planning System (SAROPS) since May 2009. During 20162017, HFR data and statistical predictions ranked 6th most popular as a source for surface current information by the United States Coast Guard and the Mid Atlantic ROMS model with HFR data assimilation reached the 4th position. HFR surface currents have been shown to reduce the search area by a factor of three in comparison with HYCOM after $96 \mathrm{~h}$, presenting much higher skill score than a global model (Roarty et al., 2010).

In Europe, significant efforts are being made to promote the use of the HFR data as reliable surface current input of the SAR emergency response and environmental modeling tools in the Iberian-Biscay-Ireland seas (e.g., the ongoing CMEMS User Uptake IBISAR project) and in Malta (Gauci et al., 2016). A first 
coordinated approach in Mediterranean Sea on SAR applications was made during the Tosca Project (Bellomo et al., 2015), involving five HF Radar sites in different countries.

\section{Hazard Detection}

A recent advancement is the use of HFR for detection of tsunami waves. The main principle for detection is that long wave orbital velocities induced by tsunamis can be detected by the HF radar as slowly varying surface currents with characteristic space and time scales. The theory for tsunami detection by HFR was first developed in the 1970s (Barrick, 1979). However, the first detection of a tsunami by an HFR did not occur until the March 2011 Tohoku tsunami in Japan, that propagated through the Pacific Ocean (Barrick and Lipa, 2011; Dzvonkovskaya et al., 2011; Lipa et al., 2011). At that time, HF radars were not equipped with real-time detection capabilities and the occurrence of the tsunami could only be identified a posteriori by analyzing the recorded data.

Real-time HFR detection of a tsunami was accomplished by a WERA HFR system installed in Tofino, Canada (Dzvonkovskaya et al., 2017). This event occurred on October 14th, 2016, when a series of severe storms were impacting the Eastern Pacific coasts. These storms were the remnants of Typhoon Songda, thus the triggering event was atmospheric in origin and there was no seismic alert issued at that time. An in-depth a posteriori analysis of the meteorological data gathered during the event, together with the recorded HF radar data in the light of an improved tsunami detection algorithm, clearly showed that two successive abnormal long waves impacted the coast, which was a meteotsunami (Guérin et al., 2018). This tsunami was first detected by the HFR $60 \mathrm{~km}$ offshore, about $45 \mathrm{~min}$ before its arrival on the coast. The meteotsunami cleared the lowest threshold of the WERA detection software and then triggered a detection at the higher threshold 20 min later, thereby confirming the presence of the oncoming wave. The current research effort is devoted to increasing the detection range (and warning time) of such events. This can be accomplished by the combination of improved detection algorithms and increased signal-to-noise ratio of the radar signal (Grilli et al., 2017). Other meteotsunami events associated with sudden changes in surface air pressure have been detected in the Netherlands (Dzvonkovskaya et al., 2018) and the East Coast of the United States (Lipa et al., 2013). New installations in Oman and the Philippines have also been motivated by the need to protect coastlines and coastal communities from hazards such as tsunamis and storm surges. It is important to remember that the performance of these systems to detect these hazards is dependent upon continuity in electrical power during such seismic or atmospheric events and this can be a problem in remote areas. Investments to increase the resiliency of the HFR systems against power outages and other failure modes should be made by the networks.

\section{Coastal Circulation}

From long-term records, a unique view of seasonal and interannual variability in surface circulation in the coastal waters of the United States have emerged with unprecedented spatial detail, together with analysis of important differences between coastal and offshore circulation. Interannual anomalies in the NE Pacific include the 2014-2015 marine heat wave, the 2015-2016 El Niño, extreme freshwater runoff in 2017, and strong upwelling in 2009. The spatial coverage of HFR allows differentiation of features such as the upwelling jets and mesoscale eddies from wind-driven circulation over the shelf and from the large-scale California Current offshore while the temporal resolution allows resolution of the time-variation of each of these phenomena independently. Seasonal shifts in the alongshore current along the United States west coast (Figure 12A) characterize the upwelling season in spring-summer with persistent strong north winds, the relaxation season in autumn with weak winds, and the winter/storm season with strong southerly wind events (Garcia-Reyes and Largier, 2012). Cross-shore currents show strong seasonality at Cape Mendocino $(\sim 40 \mathrm{~N})$ and other major headlands, where topography can steer the currents (e.g., deflection of the strong alongshore current) and mesoscale eddies can develop and persist (e.g., 1-year persistence of 100-km eddy off Cape Mendocino in 2008, Halle and Largier, 2011).

Along the east coast of the United States, similar long-term datasets show the distinct differences in mean and seasonal surface circulation between coastal waters and the Gulf Stream offshore. Plots of annual mean alongshelf flow show a gradual increase with distance offshore in the Mid-Atlantic Bight reaching a maximum near the shelf break (Figure 12B). The interannual variability of the alongshore current measured so far has a range between 3 and $11 \mathrm{~cm} / \mathrm{s}$. New insights from HFR also elucidate the eddy-driven exchange of water between coastal and offshore regions here and elsewhere (e.g., Kim et al., 2011; Rypina et al., 2016).

Over a decade of HF Radar data is also available from northern Japan, providing an unprecedented view of the distinct seasonal variation in the Soya Warm Current. Hokkaido University, has operated five HF radars along the northern coast of Hokkaido since August 2003 (Ebuchi et al., 2006). The radars cover the Soya/La Perouse Strait between Hokkaido, Japan, and Sakhalin, Russia. The Soya Warm Current enters the Sea of Okhotsk from the Sea of Japan through this strait and flows along the coast of Hokkaido as a coastal boundary current. Figure 13 shows the monthly averaged profiles of the alongshore surface current across the eastern outlet of the Strait with respect to the distance from the coast line of Hokkaido, Japan. The error bars indicate the standard deviation over 15 years from 2003 to 2018.

\section{Environmental Management}

HF Radar data are increasingly being used in support of environmental management, including short-term pollution events and long-term resource management. Specifically, data have been used in tracking the fate of runoff (Rogowski et al., 2015) and wastewater discharges in southern California, residence time in Monterey Bay (Coulliette et al., 2007), and source-sink of water parcels off northern California (Kaplan and Largier, 2006). Further, HFR data have been used in identifying circulation features that account for plankton blooms, including harmful algal blooms imported to the Ria de Vigo (Piedracoba et al., 2016) and phytoplankton delivery to the rich ecosystems of Cordell Bank and the Gulf of 
A

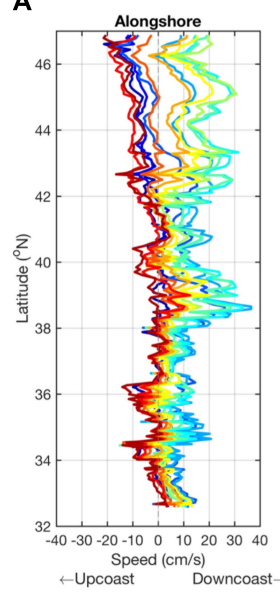

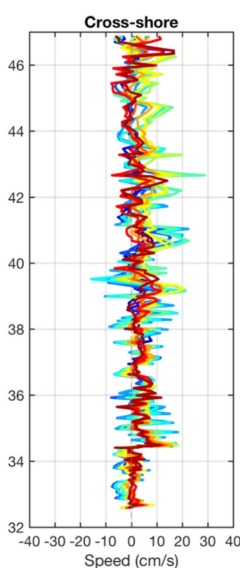

Offshor

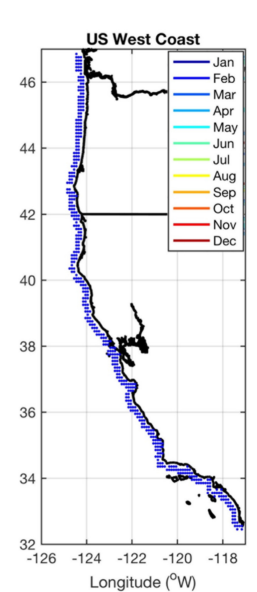

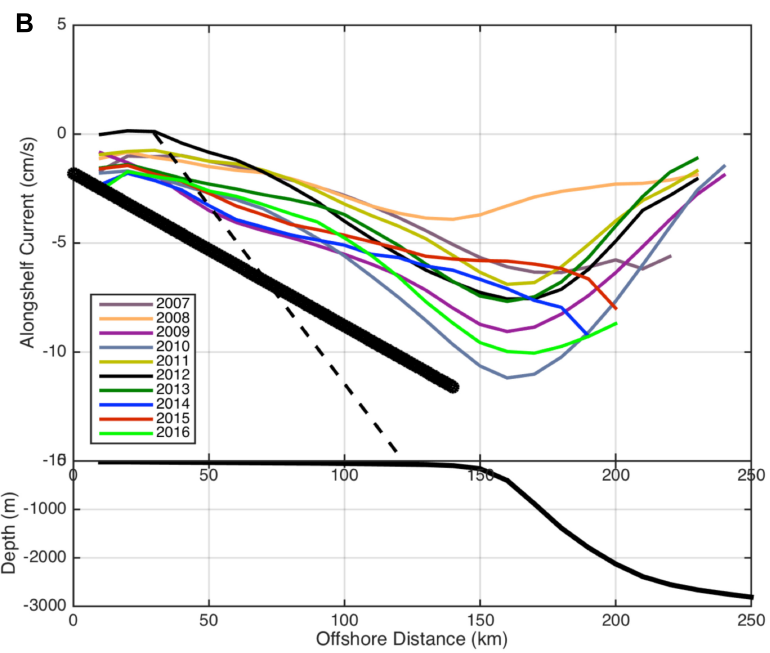

FIGURE 12 | (A) Monthly alongshore (left) and cross-shore (center) mean surface current velocities averaged from $20 \mathrm{~km}$ offshore along the United States West Coast (right). The raw HFR data were rotated to be parallel to the shore in $10 \mathrm{~km}$ segments from the Columbia River to the United States-Mexico border for each month in 2008-2017. Upcoast and onshore flows are negative whereas downcoast and offshore flows are positive. (B) Yearly alongshelf currents within the Mid Atlantic Bight of the United States East Coast from 2007 to 2016. The depth averaged alongshelf flow from Lentz model (2008) is given as the solid black line while the regression of past current meter deployments is represented by the dashed black line. Water depth (m) along the cross section is plotted below the figure.

Farallones (Halle and Largier, 2011). Other unpublished work has used these surface current data in designing networks for marine protected areas, and assessment of transport of juvenile salmonids in coastal waters. Off the west coast of the United States, HFR data are also an important component of an index of the condition of the environment for ecosystem health (Sydeman et al., 2013), been used in fishery oceanography (Nishimoto and Washburn, 2002; Bjorkstedt et al., 2010) and a recent analysis has used these data to explain anomalous and unprecedented appearance of southern species during the 2014-2015 marine heat wave (Sanford et al., 2019). These are just some examples that use HFR data to address environmental questions and inform management agencies addressing water quality, marine resources, and marine conservation.

\section{Ocean Model Validation and Assimilation}

In addition to direct use of HFR data in operational and retrospective assessment, HFR surface current data are distributed to various research and development groups that assimilate HFR-derived surface current into numerical models that simulate 3-dimensional circulation and water properties in the coastal ocean. Because of the large spatial extent and high-frequency sampling of surface currents that resolve tidal variability and small-scale topographic effects, the assimilation of these data has been shown to greatly improve model realism and confidence (e.g., Chao et al., 2018). Increasingly, this is a preferred way to deliver the value of HFR datasets as it combines the benefits of models and real data. A number of publications already exist on the assimilation of both surface currents and wave HFR data (Breivik and Sætra, 2001; Paduan and Shulman, 2004; Barth et al., 2008, 2011; Waters et al., 2013; Marmain et al., 2014; Ren et al., 2015; Sperrevik et al., 2015; Stanev et al., 2015; Iermano et al., 2016; Hernández et al., 2017 , to mention only a few examples). For the entire United
States west coast, the large-scale, high-resolution West Coast Ocean Forecast System (WCOFS) is developing a capability to assimilate HFR surface currents into a 2-km-resolution, Regional Ocean Modeling System (ROMS) numerical model (Kurapov et al., 2017). Typically, radial data are used for assimilation into regional models. An effort is underway led by University of California Santa Cruz in evaluating the impact of ocean observing system measurements on ocean analysis and forecast systems - including assessment of the best data type and the best data locations in terms of improved model realism and confidence. The project is focused on advancing ROMS (Wilkin and Hunter, 2013) through use of 4-dimensional variational data assimilation diagnostic tools to assess the impact of observations on analysis and forecasts. Indeed, the combined assimilation of the data with satellite altimetry and multi-platform observations improve both the representation of small-scale features and the understanding of the impact of coastal processes on larger scales.

While data assimilation is an exciting recent development in the use of HFR data and in realizing and delivering its value, HFR data have long been used as a very valuable data set for evaluating high-resolution numerical simulations of coastal circulation. Compared with other multi-platform observations (e.g., gliders, fixed moorings, Lagrangian drifters), HFR data are preferred as the network provides routine data at high spatio-temporal resolution comparable with the models. This cross-validation has provided an unprecedented opportunity for model assessment and contributed valuable insights into the small-scale variability of coastal ocean currents. The comparison of the mean velocity fields between model and HFR surface currents detected circulation biases in coastal models at a scale that is not properly resolved by altimetry (Mourre et al., 2018). Operationally, HFRs are increasingly considered part of core validation systems (Lorente et al., 2016; Aguiar et al., 2018) and tools like the North Atlantic Regional Validation (NARVAL), the 

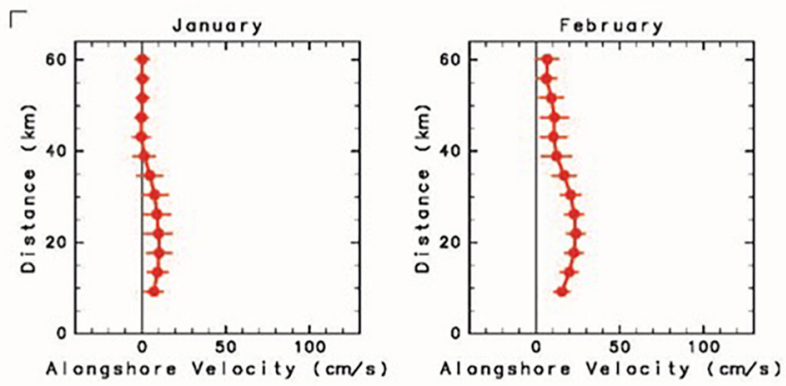

May

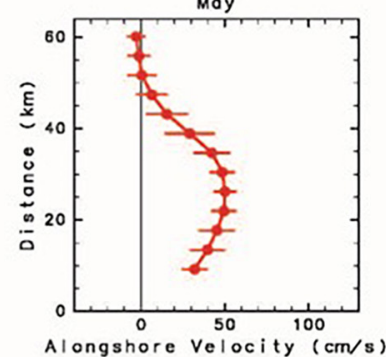

September

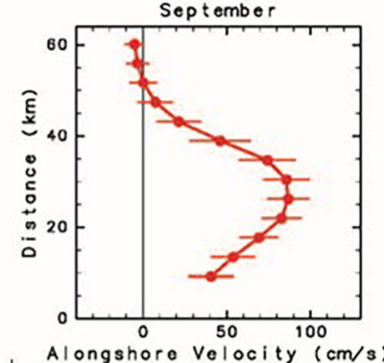

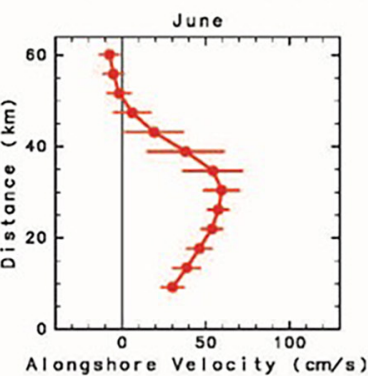

October

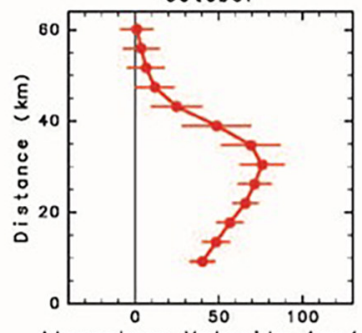

Alongshore Velocity $(\mathrm{cm} / \mathrm{s})$

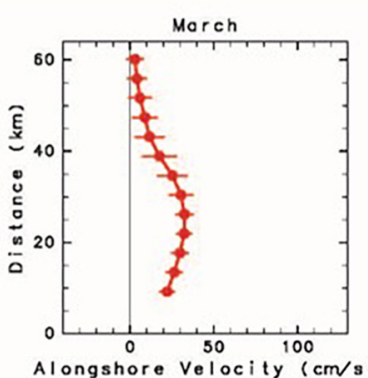

July

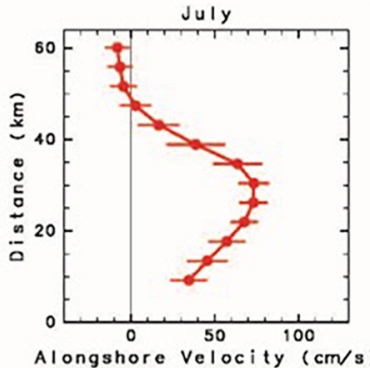

November

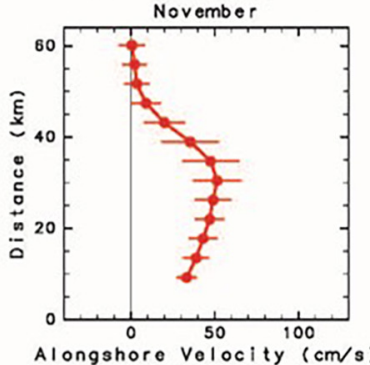

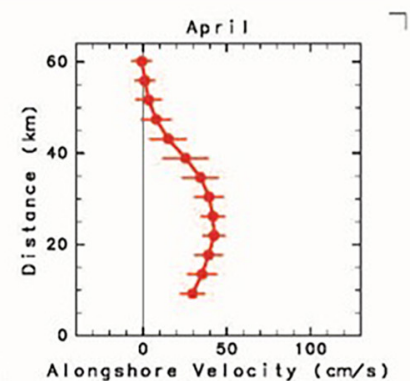
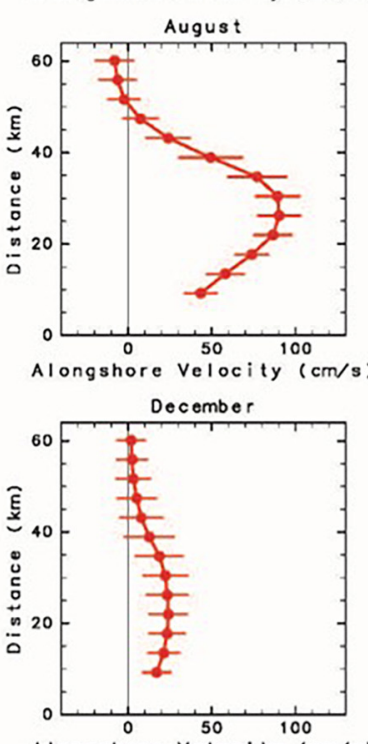

Alongshore Velocity (cm/s) L

FIGURE 13 | Monthly averaged profiles of the alongshore surface current velocity component across the eastern outlet of the Soya/La Perouse Strait with respect to the distance from the coast line of Hokkaido, Japan. The error bars indicate the standard deviation over 15 years from 2003 to 2018.

IBI-MFC forecast system validation web tool (Sotillo et al., 2015) or the SOCIB- WMOP Operational Validation System (Juza et al., 2016) are used to systematically assess model outputs at different time scales. Complementarily, HFR systems play a primary role in multi-model comparison in overlapping regions since they help in judging the strengths and weaknesses of each forecasting system in the modeling of key ocean processes and also to deepen the understanding of discrepancies in model predictions. With CMEMS regional models special emphasis has been placed on the use of HFR measurements in the intercomparison of regional models against nested coastal model solutions in order to elucidate the added value of dynamical downscaling approaches (Hernandez et al., 2018).

\section{GAPS AND FUTURE CHALLENGES}

High frequency radar technology for surface current mapping has been widely implemented in the last two decades, with a remarkable growth in applications in the last decade. In the context of the S-curve of technology development, HFR networks are in their middle age with the rapid development of new insights, applications and benefits. Globally, HFR systems are and have been operated in $25 \%$ of the countries with an ocean coastline. The Global HF Radar Network will work to develop HFR capabilities in new countries and continue its mission to increase the number of coastal radars operating around the globe by maintaining a dialogue with organizations like the Group on Earth Observations (GEO), Intergovernmental Oceanographic Commission (IOC), Joint Technical Commission for Oceanography and Marine Meteorology (JCOMM), and Partnership for Observation of the Global Ocean (POGO).

High frequency radar has proven operational value that is also well recognized through inclusion in operational protocols in the United States and elsewhere. Value is recognized specifically in rapid-response (e.g., search and rescue; oil spill) and also more recently in hazard identification and warning (e.g., tsunami). Data are used directly as well as ingested by models with operational capabilities. Further, HFR time series comprised of hourly maps of surface currents have been sustained for 10-20 years in several locations, demonstrating the value of HFR networks for retrospective assessment of environmental change, including seasonal and interannual fluctuations in 
coastal circulation and ecosystems. The Global Network has just begun conversations on developing the infrastructure to curate and serve these long data records. At the EU level, and following the recommendation given by the United States colleagues, best practices of operations and maintenance of the HFR sites are currently being developed. The development of troubleshooting guides, helping to minimize site downtime and the implementation of aids to operations and managements as well as the creation of EU technical steering teams, that could be related with the best practices working group advisor committee as expert panels are being considered in the framework of different joint proposals.

High frequency radar technology is a form of remote sensing that offers a relatively low-cost method for tracking coastal waters with both operational and environmental dividends. However, beyond the initial investment, a sustained commitment to operational up-time and data quality is essential to realize these dividends. This review of the current status of the HFR global network highlights the major challenges for data production and applications that can be addressed at a global level to properly inform choices to direct the future evolution of HFR networks as coastal ocean observing platforms. In terms of applications, further efforts are needed in the development of novel signal processing methodologies for allowing the operational delivery of other information (e.g., waves and wind maps) as well as to exploit synergy between HFR and other multi-platform observing systems (e.g., satellite, gliders, drifters). Secondly, the use of HFR surface-velocity fields for improving operational high-resolution forecast models through data assimilation is emerging strongly. Nevertheless, use of the surface current measurements to improve the model downward through the water column represents an additional challenge (Paduan and Washburn, 2013), as well as the combined assimilation of HFR data with satellite altimetry and multiplatform observations. Progress in this research will offer a unique opportunity to increase the understanding of smallscale features and their interaction with larger scale processes and feedback mechanisms. Simultaneously, the progress in observation and forecasting in the coastal ocean will allow us to develop new science-based products of high added value, enhancing the HFR data discovery and the visibility of the HFR work and applications. The development of more user-driven products will help to reinforce the HFR user's loyalty and to attract new communities, beyond academic and SAR agencies (e.g., environmental monitoring).

In terms of data production, a key overarching concern for the network is continued development of the HFR technology, sufficient supply of experienced HFR technicians and scientists and effective management of the frequency spectrum through national coordinating bodies which should hopefully limit the instances of radio frequency interference. HFR site sustainability has emerged as a challenge in those countries (e.g., Canada) where the HFR sites are owned and operated by universities in the context of finite research programs, and also in regions where HFR sites have been operated for a long time and confronted by "aging infrastructure" without renewal of hardware. One of the top priority issues is the maintenance of continued financial support to preserve the infrastructure and core service already implemented, but also funding to extend the networks at diverse national scales for an overall spatial coverage. The need for data standardization, harmonization and integration has also emerged. The future integration of the HFR data from the MARACOOS network into CMEMS-INSTAC in April 2020 (tentative date) could be considered the first step toward this goal.

An active global HFR network is crucial for pushing forward HFR scientific developments, promoting training activities, encouraging the integration of the HFRs into operational maritime monitoring and environmental assessment, and boosting networking toward an integrated, evolving and sustained HFR global network over the next decade.

\section{AUTHOR CONTRIBUTIONS}

HR, TC, PL, ER, SC, JL, and LW contributed to the main structure and content of all sections. LH contributed to Abstract, Figure 1 and Table 1, and made substantial contributions to the Introduction and Development of Networks sections. EAF and PL contributed to the European Network and Ocean Model Validation and Assimilation sections. LC, CM, AG, JM, and AR contributed to the European Network, Deployment and Maintenance Best Practices, Quality Assurance/Quality Control, and Data Access and Visualization sections. ER made substantial contributions to the writing and revising of the manuscript, particularly at the Deployment and Maintenance Best Practices, Search and Rescue, Ocean Model Validation and Assimilation, and Gaps and Future Challenges sections. LW contributed to Introduction, Europe, Africa and Middle East (Region 1), and Hazard Detection sections. JS contributed to the description of HFR in Morocco, Saudi Arabia, and Portugal, and Figure 7. $\mathrm{BW}$ and $\mathrm{KB}$ contributed to the description of HFR in Canada. $\mathrm{BH}$ contributed to the description of HFR in Chile. XF-V and KS-M contributed to the description of HFR in Mexico and Figure 8. TC contributed to the description of HFR in United States. SC contributed to the description of HFR network, data uptake, and QC in Australia. PR contributed to the description of HFR in Vietnam and Figure 10. S-HL contributed to the description of HFR in Korea and Figure 11. SP contributed to the description of HFR in Thailand. J-WL contributed to the description of HFR in Taiwan. HR contributed to Figures 24, 6, 12B, and Table 3. TC and LH contributed to Figures 5A, 9. $A R$ and JM contributed to Figure 5B. DG contributed to Figure 12A. NE contributed to Figure 13. ER and HR contributed to Table 2. C-AG and SG contributed to the Hazard Detection section. JH, ET, MO, and SG contributed to the content of all sections.

\section{FUNDING}

Korean HFR Network is supported by the Ministry of Ocean and Fisheries through the project "Base Research for Building Wide Integrated Surveillance System of Marine Territory.” 


\section{ACKNOWLEDGMENTS}

We would like to thank Zdenka Willis for the vision to establish the Global High Frequency Radar Network. We would also like to thank the NOAA IOOS, RITMARE, JERICO-NEXT,

\section{REFERENCES}

Abascal A. J., Castanedo, S., Medina, R., Losada, I. J., and Álvarez-Fanjul, E. (2009). Application of HF radar currents to oil spill modelling. Mar. Pollut. Bull. 58, 238-248. doi: 10.1016/j.marpolbul.2008.09.020

Aguiar, E., Mourre, B., Reyes, E., Hernández, J., Heslop, E., Juza, M., et al. (2018). Downscaling CMEMS Mediterranean model over the western basin: Impacts on mean flows and mesoscale eddies, in Proceedings of the 20h EGU-General Assembly 2018 of the European Geosciences Union (Vienna: EGU).

Anderson, S. (1986). "Remote sensing with the JINDALEE skywave radar." IEEE J. Ocean. Eng. 11, 158-163. doi: 10.1109/JOE.1986.1145180

Archer, M. R., Keating, S. R., Roughan, M., Johns, W. E., Lumpkin, R., BeronVera, F., Shay, L. K. (2018). The kinematic similarity of two western boundary currents revealed by sustained high-resolution observations. Geophys. Res. Lett. 45, 6176-6185. doi: 10.1029/2018GL078429

Archer, M. R., Roughan, M., Keating, S., Schaeffer, A. (2017). On the variability of the east australian current: jet structure, meandering, and influence on shelf circulation. J. Geophys. Res. Oceans 122, 8464-8481. doi: 10.1002/2017JC013097

Atan, R., Goggins, J., Hartnett, M., Nash, S., and Agostinho, P. (2015). “Assessment of extreme wave height events in Galway Bay using high frequency radar (CODAR) data," in Proceedings of the 1st International Conference on Renewable Energies Offshore (RENEW, Boca Raton, FL: CRC Press, 49-56. doi: 10.1201/ b18973-8

Barrick, D. (1977). "Extraction of wave parameters from measured HF radar seaecho doppler spectra." Radio Sci. 12, 415-424. doi: 10.1029/RS012i003p00415

Barrick, D., and Lipa, B. (2011). Japan tsunami detected by HF radars on two continents. in Proceedings of the OCEANS'11 MTS/IEEE KONA. (Waikoloa, HI: IEEE).

Barrick, D. E. (1979). “A coastal radar system for tsunami warning.” Remote Sens. Environ. 8, 353-358. doi: 10.1016/0034-4257(79)90034-8

Barrick, D. E., and Lipa, B. J. (1985). "Mapping surface currents with codar." Sea Technol. 26, 43-48.

Barth, A., Alvera-Azcárate A., and Weisberg R. H. (2008). Assimilation of highfrequency radar currents in a nested model of the West Florida Shelf. J. Geophys. Res. 113:C08033. doi: 10.1029/2007JC004585

Barth A, Alvera-Azcárate, A., Beckers, J. M., Staneva, J., Stanev, E. V., and SchulzStellenfleth, J. (2011). Correcting surface winds by assimilating HFR surface currents in the German Bight. Ocean Dynam. 61:599 doi: 10.1007/s10236-0100369-0

Baskin, C., Roarty, H., Kohut, J., and Glenn, S. (2016). Effectiveness of a bistatic system on high frequency radar resiliency. In Proceedings of the OCEANS 2016 MTS/IEEE Monterey. (Monterey, CA: IEEE). doi: 10.1109/OCEANS.2016. 7761296

Bellomo L., Griffa, A., Cosoli, S., Falco, P., Gerin, R., Iermano, I., et al. (2015). Toward an integrated HF radar network in the mediterranean sea to improve search and rescue and oil spill response: the TOSCA project experience. J. Oper. Oceanogr. 8, 95-107. doi: 10.1080/1755876X.2015.1087184

Berta, M., Bellomo, L., Griffa, A., Magaldi, M. G., Molcard, A., Mantovani, C., et al. (2018). Wind-induced variability in the Northern Current (northwestern Mediterranean Sea) as depicted by a multi-platform observing system. Ocean Sci. 14, 689-710. doi: 10.5194/os-14-689-2018

Berta, M., Bellomo, L., Magaldi, M. G., Griffa, A., Molcard, A., Marmain, J., et al. (2014b). Estimating lagrangian transport blending drifters with HF radar data and models: Results from the TOSCA experiment in the ligurian current (North Western Mediterranean Sea). Progr. Oceanogr. 128, 15-29. doi: 10.1016/ j.pocean.2014.08.004

Berta, M., Ursella, L., Nencioli, F., Doglioli, A., Petrenko, A., and Cosoli, S. (2014a). Surface transport in the Northeastern Adriatic Sea from FSLE analysis of HF radar measurements. Cont. Shelf Res. 77, 14-23. doi: 10.1016/j.csr.2014.01.016
INCREASE, SeaDataCloud, IMPACT, SICOMAR-Plus, SENERCONACyT Hidrocarburos programs and Korean Ministry of Ocean and Fisheries. We are very grateful to all the people who kindly provided the information of their radar and related activities.

Bjorkstedt, E. P., Goericke, R., McClatchie, S., Weber, E., Watson, W., and Lo, N. et al. (2010). "State of the California current 2009-2010: regional variation persists through transition from La Niña to El Niño (and back)". California Cooper. Ocean. Fish. Invest. Rep. 51, 39-69.

Boesch, D F. and Field, J C. and Scavia, D (eds.) (2000). "NOAA Coastal Ocean Program Decision Analysis Series, 21.” The Potential Consequences of Climate Variability and Change on Coastal Areas and Marine Resources: report of the Coastal Areas and Marine Resources Sector Team, U.S. National Assessment of the Potential Consequences of Climate Variability and Change, U.S. Global Change Research Program. (Silver Spring, MD: NOAA/National Centers for Coastal Ocean Science), 163

Bouksim, H., Zaidouni, Z., Merrouchi, R., (2016). HF radar pilot project in Morocco, in Proceedings of the WMO CIMO-TECO Conference, (Madrid: World Meteorological Organization).

Breivik, Ø., and Sætra, Ø. (2001). Real time assimilation of HF radar currents into a coastal ocean model. J. Mar. Syst. 28, 161-182. doi: 10.1016/S0924-7963(01) 00002-1

Chao, Y., Farrara, J. D., Zhang, H., Armenta, K. J., Centurioni, L., Chavez, F., et al. (2018). Development, implementation, and validation of a California coastal ocean modeling, data assimilation, and forecasting system. Deep Sea Res. Part 2 Top. Stud. Oceanogr. 151, 49-63. doi: 10.1016/j.dsr2.2017. 04.013

Cianelli, D., D’Alelio, D., Uttieri, M., Sarno, D., Zingone, A., Zambianchi, E., et al. (2017). Disentangling physical and biological drivers of phytoplankton dynamics in a coastal system. Sci. Rep. 7:15868. doi: 10.1038/s41598-01715880-x

Cook, T., Hazard, L., Otero, M., and Zelenke, B. (2008). Deployment and Maintenance of a High-Frequency Radar for Ocean Surface Current Mapping: Best Practices. La Jolla, CA: Southern California Coastal Ocean Observing System, 35.

Corgnati, L., Mantovani, C., Griffa, A., Berta, M., Penna, P., Celentano, P., et al. (2018a). Implementation and validation of the ismar high-frequency coastal radar network in the gulf of manfredonia (Mediterranean Sea) IEEE J. Ocean. Eng. doi: 10.1109/JOE.2018.2822518 [E-pub ahead of print].

Corgnati, L., Mantovani, C., Rubio, A., Reyes, E., Quentin, C., Cosoli, S., et al. (2018b). The European common data and metadata model for real-time High Frequency Radar surface current data, EGU General Assembly 2018. Vienna: Geophysical Research Abstracts.

Cosoli, S. Grcic, B. deVos, S., and Hetzel, Y. (2018). Improving data quality for the australian high frequency ocean radar network through real-time and delayed-mode quality-control procedures. Remote Sens. 10:1476. doi: 10.3390/ rs10091476

Coulliette, C., Lekien, F., Paduan, J. D., Haller, G., and Marsden, J. E. (2007). "Optimal pollution mitigation in Monterey Bay based on coastal radar data and nonlinear dynamics.” Environ. Sci. Technol. 41, 6562-6572. doi: 10.1021/ es0630691

de Paolo, T., and Terrill, E. (2007). "Skill assessment of resolving ocean surface current structure using compact-antenna-style hf radar and the music direction-finding algorithm." J. Atmosph. Ocean. Technol. 24, 1277-1300. doi: 10.1175/JTECH2040.1

Dzvonkovskaya, A., Figueroa, D., Gurgel, K., Rohling, H., Schlick, T. (2011). HF radar observation of a tsunami near Chile after the recent great earthquake in Japan. in Proceedings of the 2011 12th International Radar Symposium (IRS). (Leipzig: IEEE).

Dzvonkovskaya, A., Helzel, T., and Peters, H. (2018). Meteotsunami Observation by WERA Ocean Radar Systems at the Dutch Coast. in Proceedings of the 2018 OCEANS - MTS/IEEE Kobe Techno-Oceans (OTO). (Kobe: IEEE).

Dzvonkovskaya A, Petersen L, Insua TL (2017) "Real-time capability of meteotsunami detection by WERA ocean radar system". in Proceedings of the 
8th International Radar Symposium (IRS). (Prague: IEEE). doi: 10.23919/IRS. 2017.8008096

Ebuchi, N., Fukamachi, Y., Ohshima, K. I., Shirasawa, K., Ishikawa, M., Takatsuka, T., et al. (2006). Observation of the soya warm current using HF ocean radar. J. Oceanogr. 62, 47-61. doi: 10.1007/s10872-006-0031-0

Fernandes, C. (2014). Portuguese HF Radar Network - Future Plans and Consolidation, in Proceedings of the proEuroGOOS HF radar Conference, Lisbon.

Fernandez, D. M., Graber, H. C., Paduan, J. D., Barrick, D. (1997). "Mapping wind directions with HF radar." Oceanography 10, 93-95. doi: 10.5670/oceanog. 1997.33

Flament, P., Harris, D., Flament, M., Fernandez, I. Q., Hlivak, R., Flores-, X. and Marie, L. (2016). A Compact High Frequency Doppler Radio Scatterometer for Coastal Oceanography. American Geophysical Union: Washington, DC.

Flores-Vidal, X., Durazo, R., Castro, R., Navarro, L. F., Dominguez, F., Gil, E. (2015). Fine-Scale Tidal and Subtidal Variability of an Upwelling-Influenced Bay as Measured by the Mexican High Frequency Radar Observing System. Coastal Ocean Observing Systems. Amsterdam: Elsevier, 209-228. doi: 10.1016/B978-012-802022-7.00012-2

Flores-Vidal X., Durazo, R., Zavala-Sanson, L., Flament, P., Chavanne, C., Ocampo-Torres, F. J., Reyes-Hernandez, C. (2014). Evidence of inertially generated coastal-trapped waves in the eastern tropical Pacific. J. Geophys. Res. 119:2014.

Flores-Vidal, X., Durazo, R., Chavanne, C., Flament, P. (2011) Coastal circulation in the absence of wind in the Gulf of Tehuantepec, Mexico: high frequency radar observations. Ciencias Marinas 37, 493-512. doi: 10.7773/cm.v37i4A.1911

Flores-Vidal, X., Flament, P., Chavanne, C., Durazo, R., Gurgel, K.W. (2013) High frequency radars: beam steering calibrations using ships as reflectors. J. Atmosph. Ocean. Technol. 30:638-648. doi: 10.1175/JTECH-D-12-00105.1

Flores-Vidal, X., González-Montesa, S., Zertuche-Chanes, R., Rodríguez-Padilla, I., Marti, L. C., Imberger, J., et al. (2018). Three-dimensional exchange flows in a semi-enclosed bay: numerical simulations and high frequency radar observations Estuar. Coast. Shelf Sci. 210, 26-35. doi: 10.1016/j.ecss.2018. 05.027

Fujii, S., Heron, M. L., Kim, K., Lai, J.-W., Lee, S.-H., Wu, X., et al. (2013). “An overview of developments and applications of oceanographic radar networks in Asia and Oceania countries." Ocean Sci. J. 48, 69-97. doi: 10.1007/s12601-0130007-0

Garcia-Reyes, M., and Largier, J. L. (2012). Seasonality of coastal upwelling off central and northern California: new insights including temporal and spatial variability. J. Geophys. Res. 117:C03028: doi: 10.1029/2011JC007629

Gauci, A., Drago, A., Abela, J. (2016) Gap filling of the calypso hf radar sea surface current data through past measurements and satellite wind observations. Int. J. Navig. Observ. 2016:2605198. doi: 10.1155/2016/2605198

Gómez, R., Helzel, T., Wyatt, L., Lopez, G., Conley, D., Thomas, N., et al. (2015). "Estimation of wave parameters from HF radar using different methodologies and compared with wave buoy measurements at the Wave Hub". Paper presented at OCEANS 2015 - MTS/IEEE, Genova. doi: 10.1109/OCEANSGenova.2015.7271477

Grilli, S. T., Guérin, C.-A., Shelby, M., Grilli, A. R., Moran, P., Grosdidier, S., Insua, T. L. (2017) "Tsunami detection by high frequency radar beyond the continental shelf: ii. extension of time correlation algorithm and validation on realistic case studies”. Pure Appl. Geophys. 174, 3003-3028. doi: 10.1007/s00024-017-1619-6

Guérin, C.-A., Grilli, S. T., Moran, P., Grilli, A. R., Insua, T. L. (2018). "Tsunami detection by high-frequency radar in British Columbia: performance assessment of the time-correlation algorithm for synthetic and real events". Ocean Dynam. 68, 423-438. doi: 10.1007/s10236-018-1139-7

Halle, C. M., and Largier, J. L. (2011). Surface circulation downstream of the Point Arena upwelling center. Cont. Shelf Res. 31, 1260-1272. doi: 10.1016/j.csr.2011. 04.007

Harlan, J., Terrill, E., Hazard, L., Keen, C., Barrick, D., Whelan, C., et al. (2010). "The integrated ocean observing system high-frequency radar network: status and local, regional, and national applications." Mar. Technol. Soc. J. 44, 122-132. doi: 10.4031/MTSJ.44.6.6

Harlan, J., Terrill, E., Hazard, L., Otero, M., Roarty, H. (2015). The Integration Ocean Observing System HF Radar Network. in Proceedings of the OCEANS 2015-MTS/IEEE. Washington, DC. doi: 10.23919/OCEANS.2015.7404587
Headrick, J. M., and Thomason, J. F. (1998). "Applications of high-frequency radar." Radio Sci. 33, 1045-1054. doi: 10.1029/98RS01013

Heesemann, M., Insua, T. L., Scherwath, M., Juniper, S. K., Moran, K. (2014). "Ocean Networks Canada: from geohazards research laboratories to smart ocean systems.” Oceanography 27, 151-153. doi: 10.5670/oceanog.2014.50

Helzel, T., Kniephoff, M., and Petersen, L. (2007). Features and limitations of the modular oceanography radar system WERA. in Proceedings of the OCEANS 2007-Europe, Aberdeen. doi: 10.1109/OCEANSE.2007.4302421

Hernandez, F., Smith, G., Baetens, K., Cossarini, G., Garcia-Hermosa, I., Drevillon, M. et al., (2018). "Measuring performances, skill and accuracy in operational oceanography: New challenges and approaches,".in New Frontiers in Operational Oceanography, eds E. Chassignet, A. Pascual, J. Tintoré and J. Verron (Tallahassee: GODAE OceanView), 759-796. doi: 10.17125/gov2018. $\operatorname{ch} 29$

Hernández, J., Mourre, B., Reyes, E., Marmain, J., Orfila, A., Tintoré, J., (2017) Model Velocities Assessment and HF Radar Data Assimilation in the Ibiza Channel. Vienna: EGU General Assembly, 23-28.

Hernández-Carrasco, I., Orfila, A., Rossi, V., Garçon, V. (2018) Effect of small scale transport processes on phytoplankton distribution in coastal seas. Sci. Rep. 8:8613. doi: 10.1038/s41598-01826857-9

Iermano, I., Moore, A. M., and Zambianchi, E. (2016). Impacts of a 4-dimensional variational data assimilation in a coastal ocean model of southern Tyrrhenian Sea. J. Mar. Sys. 154, 157-171. doi: 10.1016/j.jmarsys.2015.09.006

Juza, M., Mourre, B., Renault, L., Gómara, S., Sebastián, K., Lora, S., et al. (2016) SOCIB operational ocean forecasting system and multi-platform validation in the Western Mediterranean Sea. J. Operat. Oceanogr. 9, s155-s166. doi: 10.1080/ 1755876X.2015.1117764

Kalampokis, A., Uttieri, M., Poulain, P.-M., and Zambianchi, E. (2016) Validation of HF radar-derived currents in the Gulf of Naples with Lagrangian data. IEEE Geosci. Remote Sens. Lett. 13, 1452-1456. doi: 10.1109/LGRS.2016. 2591258

Kaplan, D. M., and Largier, J. L. (2006). HF-radar-derived origin and destination of surface waters off Bodega Bay, California. Deep Sea Res. II 53, 2906-2930. doi: 10.1016/j.dsr2.2006.07.012

Kerry, C., Powell, B., Roughan, M., Oke, P. (2016). Development and evaluation of a high-resolution reanalysis of the East Australian Current region using the regional ocean modelling system (ROMS 3.4) and incremental strongconstraint 4-dimensional variational (IS4D-Var) data assimilation. Geosci. Model. Dev. 9, 3779-3801. doi: 10.5194/gmd-9-3779-2016

Kim, H.-K., Kim, J.-H., Son, Y.-T., and Lee, S.-H. (2018). An overview of operations and applications of hf ocean radar networks in the korean coast. (review). Korean J. Remote Sens. 34, 351-375.

Kim, S. Y., Terrill, E. J., Cornuelle, B. D., Jones, B., Washburn, L., Moline, M. A., et al. (2011). Mapping the U.S. West Coast surface circulation: a multiyear analysis of high-frequency radar observations. J. Geophys. Res. 116:C03011. doi: 10.1029/2010JC006669

Kirincich, A. (2016). Remote sensing of the surface wind field over the coastal ocean via direct calibration of HF radar backscatter power. J. Atmosph. Oce. Techn. 33(7), 1377-1392. doi: 10.1175/JTECH-D-15-0242.1

Kurapov, A. L., Erofeeva, S. Y., and Myers, E. (2017). Coastal sea level variability in the US West Coast Ocean Forecast System (WCOFS). Ocean Dyn. 67, 23-36. doi: 10.1007/s10236-016-1013-4

Lee, S.-H and Heron, M. L., (2013). Development of oceanographic radar networks, data management and applications in asia and oceania countries. Ocean Sci. J. 48, 67-68. doi: 10.1007/s12601-013-0006-1

Lee, S.-H., Kang, C.-Y., Choi, B.-J., and Kim, C.-S. (2013). Surface current response to wind and plumes in a bay-shape estuary of the eastern Yellow Sea: Ocean radar observation. Ocean Sci. J. 48, 117-139. doi: 10.1007/s12601-013-0010-5

Lipa, B., Arrick, D. B., Saitoh, S., Ishikawa, Y., Awaji, T., Largier, J. and Garfield, N. (2011). Japan tsunami current flows observed by HF Radars on two continents. Remote Sens. 3, 1663-1679. doi: 10.3390/rs3081663

Lipa, B., Parikh, H., Barrick, D., Roarty, H., Glenn, S. (2013) High-frequency radar observations of the June 2013 US East Coast meteotsunami. Nat. Hazards 74, 109-122. doi: 10.1007/s11069-013-0992-4

Lipa, B., Whelan, C., Rector, B., and Nyden, B. (2009). "HF radar bistatic measurement of surface current velocities: drifter comparisons and radar consistency checks." Remote Sens. 1, 1190-1211. doi: 10.3390/rs1041190 
Lipa, B. J., Barrick, D. E., Isaacson, J., and Lilleboe, P. M. (1990). “CODAR wave measurements from a North Sea semisubmersible.” IEEE J. Ocean. Eng. 15, 119-125. doi: 10.1109/48.50697

Lipa, B., and Nyden, B. (2005). "Directional wave information from the SeaSonde." Ocean. Eng. 30, 221-231. doi: 10.1109/JOE.2004.839929

Liu, Y., and Weisberg, R. H. (2007) "Ocean currents and sea surface heights estimated across the West Florida Shelf”. J. Phys. Oceanogr. 37, 1697-1713. doi: 10.1175/JPO3083.1

Lorente, P., Piedracoba, S., Soto-Navarro, J., and Álvarez-Fanjul, E. (2014) "Accuracy assessment of high frequency radar current measurements in the Strait of Gibraltar" J. Operat. Oceanogr. 7, 59-73. doi: 10.1080/1755876X.2014. 11020300

Lorente, P., Sotillo, M. G., Aouf, L., Amo-Baladrón, A., Barrera, E., Dalphinet, A., et al. (2018). "Extreme wave height events in nw spain: a combined multi-sensor and model approach“. Remote Sens. 10:1. doi: 10.3390/rs10010001

Lorente, P., Piedracoba, S., Sotillo, M. G., Aznar, R., Amo-Balandron, A., Pascual, A.,et al. (2016) "Ocean model skill assessment in the NW Mediterranean using multi-sensor data” J. Operat. Oceanogr. 9, 75-92. doi: 10.1080/1755876X.2016.1215224

Lumpkin, R., Grodsky, S. A., Centurioni, L., Rio, M., Carton, J. A., and Lee, V. (2013): Removing spurious low-frequency variability in drifter velocities. J. Atmos. Oceanic Technol. 30, 353-360. doi: 10.1175/JTECH-D-1200139.1

Mader, J., Rubio, A., Asensio, J. L., Novellino, A., Alba, M., Corgnati, L., et al. (2016). The European HF Radar Inventory. Pasaia: EuroGOOS publications.

Mantovanelli, A., Keating, S., Wyatt, L. R., Roughan, M., Schaeffer, A. (2017). "Lagrangian and Eulerian characterization of two counterrotating submesoscale eddies in a western boundary current" J. Geophys. Res. Oceans 122, 4902-4921. doi: 10.1002/2016JC011968

Marmain, J., Molcard, A., Forget, P., Barth, A. (2014). Assimilation of HF radar surface currents to optimize forcing in the North Western Mediterranean Sea, Nonlinear Process. Geophys. 21, 659-675. doi: 10.5194/npg-21-659-2014

Menna, M., Mercatini, A., Uttieri, M., Buonocore, B., Zambianchi, E. (2007). Wintertime transport processes in the Gulf of Naples investigated by HF radar measurements of surface currents. Nuovo Cimento 6, 605-622.

Mihanovic, H., Pattiaratchi, C., Verspecht, F. (2016). "Diurnal sea breezes force near-inertial waves along rottnest continental Shelf, Southwestern Australia". J. Phys. Oceanogr. 46, 3487-3508. doi: 10.1175/JPO-D-16-0022.1

Mourre, B., Aguiar, E., Juza, M., Hernández-Lasheras, J., Reyes, E., Heslop, E., et al. (2018) Assessment of high-resolution regional ocean prediction systems using multi-platform observations: Illustrations in the Western Mediterranean Sea., in New Frontiers in Operational Oceanography, eds E. P Chassignet, A. Pascual, J. Tintoré, J. Verron (Tallahassee: GODAE OceanView), 815. doi: 10.17125/ gov2018.ch24

Nishimoto, M. N., and Washburn, L. (2002). Patterns of coastal eddy circulation and abundance of pelagic juvenile fish in the Santa Barbara Channel, California, USA. Mar. Ecol. Progr. Ser. 241, 183-199. doi: 10.3354/meps241183

Ohlmann, C., White, P., Washburn, L., Emery, B., Terrill, E., and Otero, M. (2007). "Interpretation of coastal HF radar-derived surface currents with highresolution drifter data”. J. Atmosp. Ocean. Technol. 24, 666-680. doi: 10.1175/ JTECH1998.1

Paduan, J. D., and Shulman, I. (2004). HF radar data assimilation in the Monterey Bay area. J. Geophys. Res. Oceans 109, 1-17. doi: 10.1029/2003JC001949

Paduan, J. D., and Washburn, L. (2013) High-frequency radar observations of ocean surface currents. Ann. Rev. Mar. Sci. 5, 115-136. doi: 10.1146/annurevmarine-121211-172315

Piedracoba, S., Rosón, G., and Varela, R. A. (2016). Origin and development of recurrent dipolar vorticity structures in the outer Ría de Vigo (NW Spain). Cont. Shelf Res. 118, 143-153. doi: 10.1016/j.csr.2016.03.001

Ponsford, A. M., Dizaji, R. M., and McKerracher, R. (2003). HF surface wave radar operation in adverse conditions. In Proceedings of the International Conference on Radar (IEEE Cat. No. 03EX695), IEEE doi: 10.1109/RADAR.2003.1278808

Quentin, C. G., Zakardjian, B., Marié, L., Rubio, A., Dumas, F., Sentchev, A., et al. (2017). "Progress towards a french high frequency ocean surface wave radar network." Merc. Ocean J. 55, 25-38.

Ren, L., Nash, S., and Hartnett, M. (2015). Observation and modeling of tideand wind-induced surface currents in Galway Bay. Water Sci. Eng. 8, 345-352. doi: $10.1016 /$ j.wse.2015.12.001
Roarty, H., Hazard, L., and Alvarez, E. (2016). Growing Network of Radar Systems Monitors Ocean Surface Currents. Washington, DC: EOS.

Roarty, H., Hazard, L., Wyatt, L., Harlan, J., and Alvarez Fanjul, E. (2014) The Global High Frequency Radar Network Available at: https://earthzine.org/theglobal-high-frequency-radar-network/ (accessed October 30, 2014).

Roarty, H. J., Glenn, S. M., Kohut, J. T., Gong, D. Handel, E., Rivera Lemus, E., et al. (2010). "Operation and application of a regional high frequency radar network in the mid atlantic bight." Mar. Technol. Soc. J. 44, 133-145. doi: 10.4031/MTSJ.44.6.5

Rogowski, P. A., Terrill, E., Schiff, K., and Kim, S.-Y. (2015). An assessment of the transport of southern California stormwater ocean discharges. Mar. Poll. Bull. 90, 135-142. doi: 10.1016/j.marpolbul.2014.11.004

Rubio, A., Caballero, A., Orfila, A., Hernández-Carrasco, I., Ferrer, L., González, M., et al. (2018a) Eddy-induced cross-shelf export of high Chl-a coastal waters in the SE Bay of Biscay. Remote Sens. Environ. 205, 290-304. doi: 10.1016/j.rse.2017.10.037

Rubio, A., Mader, J., Corgnati, L., Mantovani, C., Griffa, A., Novellino, A., et al. (2018b). "Present and future of the European HF radar network: outcomes of the INCREASE project. A, 2018," in Proceeding of the 4th Orca meeting, Okinawa.

Rubio, A., Mader, J., Corgnati, L., Mantovani, C., Griffa, A., Novellino, A., et al. (2017). HF radar activity in European coastal seas: next steps towards a pan-European HF radar network, Front. Mar. Sci. 4:8. doi: 10.3389/fmars.2017. 00008

Rypina, I. I., Kirincich, A., and Lentz, S. J. (2016). Investigating the eddy diffusivity concept in the coastal ocean. J. Phys. Oceangr. 46, 2201-2218. doi: 10.1175/JPOD-16-0020.1

Sanford, E., Sones, J. L., García-Reyes, M., Goddard, J. H. R. and Largier, J. L. (2019). "Widespread shifts in the coastal biota of northern California during the 2014-2016 marine heatwaves." Sci. Rep. 9:4216. doi: 10.1038/s41598-01940784-3

Schaeffer, A., Gramoulle, A., Roughan, M., Mantovanelli, A. (2017). Characterizing frontal eddies along the East Australian current from HF radar observations. J. Geophys. Res. Oceans 122, 3964-3980. doi: 10.1002/2016JC0 12171

Send, U., Davis, R., Fischer, J., Imawaki, S., Kessler, W., Meinen, C., et al. (2009). "A global boundary current circulation observing network," in Proceedings of OceanObs'09: Sustained Ocean Observations and Information for Society, Venice.

Sentchev, A., Forget, P., Barbin, Y., Yaremchuk, M. (2013). Surface circulation in the Iroise Sea (W. Brittany) from high resolution HF radar mapping. J. Mar. Syst. 109-110, S153-S168. doi: 10.1016/j.jmarsys.2011.11.024

Small, C., and Nicholls, R. J. (2003). A global analysis of human settlement in coastal zones. J. Coast. Res. 19, 584-599.

Solabarrieta, L., Aspey, R., Jones, B., (2018). “A New Insight into the Physical Processes of the Red Sea Using High Frequency Radar Data," in Proceedings of the Ocean Sciences Conference, Portland, 11-16.

Solabarrieta, L., Frolov, S., Cook, M., Paduan, J., Rubio, A., González, M., et al. (2016). Skill assessment of HF radar-derived products for Lagrangian simulations in the Bay of Biscay. J. Atmos. Oceanic Technol. 3, 2585-2597. doi: 10.1175/JTECH-D-16-0045.1

Son, Y.-T., Lee, S.-H., Kim, C.-S., Chul Lee, J., and Lee, G.-H. (2007). "Surface current variability in the Keum River Estuary (South Korea) during summer 2002 as observed by high-frequency radar and coastal monitoring buoy." Cont. Shelf Res. 27, 43-63. doi: 10.1016/j.csr.2006.08.008

Sotillo, M. G., Cailleau, S., Lorente, P., Levier, B., Aznar, R., Reffray, G., et al. (2015) The MyOcean IBI ocean forecast and reanalysis systems: operational products and roadmap to the future copernicus service. J. Operat. Oceanogr. 8, 63-79. doi: 10.1080/1755876X.2015.1014663

Sperrevik, A. K., Christensen, K. H., and Röhrs, J. (2015). Constraining energetic slope currents through assimilation of high-frequency radar observations. Ocean Sci. 11, 237-249. doi: 10.5194/os-11-237-2015

Stanev, E. V., Ziemer, F., Schulz-Stellenfleth, J., Seemann, J., Staneva, J., Gurgel, K.-W. (2015). Blending surface currents from HF Radar observations and numerical modeling: tidal hindcasts and forecasts. J. Atmos. Ocean. Technol. 32, 256-281. doi: 10.1175/JTECH-D-13-00164.1

Stewart, J. R., Gast, R. J., Fujioka, R. S., Solo-Gabriele, H. M., Meschke, J. S., Amaral-Zettler, L. A., et al. (2008). “The coastal environment and human health: 
microbial indicators, pathogens, sentinels and reservoirs". Environ. Health 7:S3. doi: 10.1186/1476-069X-7-S2-S3

Sydeman, W. J., Thompson, S. A., Garcia-Reyes, M., Kahru, M., Peterson, W. T., and Largier, J. L. (2013). Multivariate ocean-climate indicators (MOCI) for the central California current: Environmental change 1990-2010. Prog. Oceanogr. 120, 352-369. doi: 10.1016/j.pocean.2013.10.017

U.S. Integrated Ocean Observing System [IOOS] (2015). A Plan to Meet the Nation's Needs for Surface Current Mapping, 2015 Prepared for the Interagency Working Group on Ocean Observations. Silver Spring, MD: IOOS, 62 .

U.S. Integrated Ocean Observing System [IOOS] (2016). Manual for Real-Time Quality Control of High Frequency Radar Surface Currents Data: A Guide to Quality Control and Quality Assurance of High Frequency Radar Surface Currents Data Observations. Silver Spring, MD: IOOS, 58.

U.S. Integrated Ocean Observing System [IOOS] (2017). QARTOD Project Plan Accomplishments for 2012-2016 and Update for 2017-2021. Silver Spring, MD: IOOS.

Updyke, T. (2017) A study of HF Radar Outages in the Mid-Atlantic. Galveston: Radiowave Operators Working Group (ROWG).

Uttieri, M. Cianelli, D., Buongiorno Nardelli, B., Buonocore, B., Falco, P., Colella, S., Zambianchi, E. (2011). Multiplatform observation of the surface circulation in the Gulf of Naples (Southern Tyrrhenian Sea), Ocean Dyn. 61, 779-796. doi: 10.1007/s10236-011-0401-z

Vignudelli, S., Cipollini, P., Roblou, L., Lyard, F., Gasparini, G. P., Manzella, G., et al. (2005): Improved satellite altimetry in coastal systems: case study of the Corsica Channel (Mediterranean Sea). Geophys. Res. Lett. 32:L07608. doi: 10.1029/2005GL022602

Wandres, M., Wijeratne, E. M. S., Cosoli, S., Pattiaratchi, C. (2017). The effect of the Leeuwin Current on offshore surface gravity waves in southwestwestern Australia. J. Geophys. Res. Oceans 122, 9047-9067. doi: 10.1002/2017JC0 13006

Waters, J., Wyatt, L. R., Wolf, J., and Hines, A. (2013). "Data assimilation of partitioned HF radar wave data into Wavewatch III”. Ocean Model. 72, 17-31. doi: 10.1016/j.ocemod.2013.07.003
Wilkin, J. L., and Hunter, E. J. (2013), An assessment of the skill of real-time models of Mid-Atlantic Bight continental shelf circulation, J. Geophys. Res. Oceans 118, 2919-2933. doi: 10.1002/jgrc.20223

Wyatt, L. R. (2018). A comparison of scatterometer and HF radar wind direction measurements. J. Oper. Oceanogr. 11, 54-63. doi: 10.1080/1755876X.2018. 1443625

Wyatt, L. R., Green, J. J., Middleditch, A., Moorhead, M. D., Howarth, J., Holt, M., et al. (2006). "Operational wave, current, and wind measurements with the pisces HF radar.” IEEE J. Ocean. Eng. 31, 819-834. doi: 10.1109/JOE.2006. 888378

Wyatt, L. R., and Green, J. J. (2009). "Measuring high and low waves with HF radar", in Proceedings of the OCEANS 2009-EUROPE. Bremen: IEEE. doi: 10.1109/OCEANSE.2009.5278328

Wyatt, L. R., Green, J. J., and Middleditch, A. (2011). "HF radar data quality requirements for wave measurement”. Coast. Eng. 58, 327-336. doi: 10.3390/ s150407412

Conflict of Interest Statement: BW was employed by company OEA Technologies, Inc. BH was employed by company HELZEL Messtechnik $\mathrm{GmbH}$. JS was employed by company Qualitas Remos.

The remaining authors declare that the research was conducted in the absence of any commercial or financial relationships that could be construed as a potential conflict of interest.

Copyright (c) 2019 Roarty, Cook, Hazard, George, Harlan, Cosoli, Wyatt, Alvarez Fanjul, Terrill, Otero, Largier, Glenn, Ebuchi, Whitehouse, Bartlett, Mader Rubio, Corgnati, Mantovani, Griffa, Reyes, Lorente, Flores-Vidal, Saavedra-Matta, Rogowski, Prukpitikul, Lee, Lai, Guerin, Sanchez, Hansen and Grilli. This is an open-access article distributed under the terms of the Creative Commons Attribution License (CC BY). The use, distribution or reproduction in other forums is permitted, provided the original author(s) and the copyright owner(s) are credited and that the original publication in this journal is cited, in accordance with accepted academic practice. No use, distribution or reproduction is permitted which does not comply with these terms. 